\title{
Functional Impact of Post-exercise Cooling and Heating on Recovery and Training Adaptations: Application to Resistance, Endurance, and Sprint Exercise
}

Thomas Chaillou ${ }^{1 *}\left(\mathbb{0}\right.$, Viktorija Treigyte ${ }^{2}$, Sarah Mosely ${ }^{3}$, Marius Brazaitis ${ }^{2}$, Tomas Venckunas $^{2}$ (i) and Arthur J. Cheng ${ }^{3}$ (D)

\begin{abstract}
The application of post-exercise cooling (e.g., cold water immersion) and post-exercise heating has become a popular intervention which is assumed to increase functional recovery and may improve chronic training adaptations. However, the effectiveness of such post-exercise temperature manipulations remains uncertain. The aim of this comprehensive review was to analyze the effects of post-exercise cooling and post-exercise heating on neuromuscular function (maximal strength and power), fatigue resistance, exercise performance, and training adaptations. We focused on three exercise types (resistance, endurance and sprint exercises) and included studies investigating (1) the early recovery phase, (2) the late recovery phase, and (3) repeated application of the treatment. We identified that the primary benefit of cooling was in the early recovery phase ( $<1 \mathrm{~h}$ post-exercise) in improving fatigue resistance in hot ambient conditions following endurance exercise and possibly enhancing the recovery of maximal strength following resistance exercise. The primary negative impact of cooling was with chronic exposure which impaired strength adaptations and decreased fatigue resistance following resistance training intervention (12 weeks and 4-12 weeks, respectively). In the early recovery phase, cooling could also impair sprint performance following sprint exercise and could possibly reduce neuromuscular function immediately after endurance exercise. Generally, no benefits of acute cooling were observed during the 24-72-h recovery period following resistance and endurance exercises, while it could have some benefits on the recovery of neuromuscular function during the 24-48-h recovery period following sprint exercise. Most studies indicated that chronic cooling does not affect endurance training adaptations following 4-6 week training intervention. We identified limited data employing heating as a recovery intervention, but some indications suggest promise in its application to endurance and sprint exercise.
\end{abstract}

Keywords: Cooling, Heating, Water immersion, Training, Muscle function, Physical performance, Temperature, Fatigue, Recovery

*Correspondence: thomas.chaillou@oru.se

1 School of Health Sciences, Örebro University, 70182 Örebro, Sweden Full list of author information is available at the end of the article

\section{Key Points}

- The primary benefit of cooling is observed during the early recovery phase $(<1 \mathrm{~h}$ post-exercise): it can improve fatigue resistance after an initial endurance exercise performed in hot ambient conditions and could possibly enhance the recovery of maximal strength following resistance exercise. 
- Repeated post-exercise cooling appears to blunt muscle strength adaptations and decrease fatigue resistance following resistance training (12 weeks and 4-12 weeks, respectively). In the early recovery phase, cooling could also impair sprint performance when executed $<1 \mathrm{~h}$ following initial sprint exercises, and some studies indicate that it could possibly reduce neuromuscular function immediately after endurance exercise.

- Single application of cooling has generally no effect during the 24-72-h recovery period following resistance and endurance exercises, while it could have some benefits on the recovery of neuromuscular function during the 24-48-h recovery period following sprint exercise. Repeated exposures to cooling do not seem to affect endurance training adaptations following 4-6-week training interventions. To date, there are a limited number of studies employing heating as a recovery intervention, but some indications suggest promise in its application to endurance and sprint exercise.

\section{Introduction}

Various forms of exercise exist and are positioned on a continuum, with endurance exercise on one side, resistance exercise on the other side, and sprint exercise somewhere in-between. Most sporting events and exercise training sessions include one or a combination of these exercise forms. Accelerating acute recovery of neuromuscular function and physical performance after exercise is crucial for enhancing the quality of subsequent training sessions or maximizing athletic performance in multiday competitions. In addition, improving physical recovery is beneficial for increasing the total training volume in trained athletes, which would enhance training adaptations while potentially avoiding overtraining and injury. Applying additional physiological stresses during postexercise recovery could also be relevant for enhancing training adaptations [1].

The use of cooling such as cold-water immersion (CWI) has become a popular post-exercise recovery intervention based on the assumption that it can enhance the restoration of physical performance and augment chronic adaptations to training. Cooling has generally been thought to improve recovery by reducing the feelings of muscle soreness, alleviating exercise-induced muscle damage, and decreasing inflammation and edema, as has been discussed in previous reviews [2-6]. Application of local heating is more commonly used in the rehabilitation setting to treat musculoskeletal injuries or to protect muscle from potential damage $[7,8]$. Although frequently used by athletes, its impact on post-exercise recovery and performance has not been extensively investigated $[3,7]$.

Numerous reviews have analyzed the potential effects of cooling [2-6, 9-11] or heating (combined or not with cooling) $[2,3,5,7,10]$ on post-exercise recovery and training adaptations. In the current review, we postulate that cooling or heating could improve or worsen postexercise recovery and training adaptations depending on the form of exercise (endurance, resistance or sprint exercise) given that the mechanism of exercise-induced fatigue, and thus the potential recovery mechanisms involved, are known to be task-dependent [12, 13]. Furthermore, the most relevant measure of performance outcome relates to neuromuscular function, as determined by maximal strength and power. It was recently acknowledged that there is a relative lack of research studies in this field that focus on strength and power assessment [14], and determining the effectiveness of cooling and/or heating on functional outcome measures has also not been the main focus of recent reviews exploring the role of post-exercise cooling or heating [3, $4,7]$. Thus, the current review will delineate the available evidence as to whether post-exercise cooling and/ or heating are detrimental or beneficial for the recovery of neuromuscular function, fatigue resistance, physical performance, and training adaptations. Our review will include research articles that studied the effects of single and repeated applications of cooling or heating following exercise (resistance, endurance or sprint exercises). These studies will be categorized into those that investigated (1) the early acute phase of recovery (up to $9.5 \mathrm{~h}$ following exercise: recovery time between two exercise sessions performed within the same day), (2) the late acute phase of recovery (24-72 $\mathrm{h}$ following exercise: recovery time between exercise sessions performed on separate days), and (3) repeated application of the treatment. We will also outline some potential mechanisms involved and will outline key points at the end of each section.

\section{Definition of Exercise Forms and Modes of Cooling and Heating}

Resistance exercise, traditionally defined as short exercise executed at high loads with few repetitions, is the most common form of strength training [1]. Studies involving purely eccentric exercises were not included in this category because these exercises cause severe muscle damage and represent an extreme situation that is less functionally relevant to traditional strength training regimes. Acute resistance exercise typically entailed a total of 4-16 sets at 8-20 repetitions involving a single form of exercise or a combination of exercises, and training interventions corresponded to 4-12 weeks of resistance training 
(2-3 sessions per week including 3-6 sets at 8-20 repetitions for each exercise) (Table 1).

Endurance exercise encompasses prolonged exercise performed at intensities below or close to maximal oxygen uptake $\left(\mathrm{VO}_{2 \max }\right)$ that highly stimulates the cardiorespiratory system and aerobic metabolism. Prolonged exercises consisting of numerous interval bouts performed at high intensities (near $\mathrm{VO}_{2 \max }$, all-out sprints excluded) and interspaced with efforts performed at lower intensity were also included in this category. Prolonged exercise sessions combining repetitive all-out sprints and moderate/high intensity aerobic exercises were excluded from this review since a purpose of this study was to isolate the effects of treatment on specific forms of exercise $[15,16]$. Acute endurance exercise usually included continuous or interval bouts of cycling or running performed for $\sim 30 \mathrm{~min}$ up to $3-4 \mathrm{~h}$ (Table 2). Chronic exercise consisted of 4-5 weeks of predominantly endurance training (3-4 sessions/week up to 2.5-4 h/day) (Table 2).

Sprint exercise included a few bouts (2-12) of all-out sprints (from $\sim 15 \mathrm{~s}$ up to $\sim 90 \mathrm{~s}$ ) interspersed with prolonged recovery periods (at least 8 times the duration of the sprint) (Table 3). Only one study investigated chronic adaptations to sprint training (3 cycling sessions/week for 6 weeks) when combined with post-exercise CWI [17] (Table 3). The physical and physiological demands of team-sports activities require the repetition of high to maximal efforts such as sprints, jumps, kicks and tackles (i.e., sprint exercises and strength exercises) interspersed with efforts at low/moderate intensity (i.e., endurance exercise) [18]. Thus, exercise-induced fatigue in team sports is likely the result of numerous confounding factors. Although the literature related to post-exercise cooling is rather extensive in team sports [5], we purposely did not include this topic in the current review since the purpose here is to isolate the effects of treatment based on specific forms of exercise.

Various modes of cooling and heating have been described in a recent review [3]. Here, we included studies employing post-exercise CWI of the exercised limbs or whole-body CWI (immersion up to the neck or including the head). The majority of these studies used immersion into $5-20{ }^{\circ} \mathrm{C}$ water for $5-30 \mathrm{~min}$ (see Tables 1,2 , 3). We also included some studies employing ice-chilled cuffs and other body cooling systems [19-21]. The few studies employing post-exercise heating used hot water immersion (HWI) of the lower limbs or whole-body HWI (38-40 ${ }^{\circ} \mathrm{C}$ for $\left.15-40 \mathrm{~min}\right)$ [16, 22-24], hot water-perfused arm-cuff [19] or heat pad [25] (see Tables 1, 2, 3). Contrast water therapy (CWT), which consists of alternating CWI and HWI for 10-30 min, is also commonly used during recovery, in particular after endurance exercise (see Table 2). Studies included in this review only employed water immersion or methods that cover the exercised limbs (cuffs and pads). A cryotherapy chamber cools the air while conversely sauna heats it, and similarly to water, air is a medium that cools/heats the body by convection and conduction. However, water is $>800$ times denser than air [26], and the thermal conductivity by water is 25 times greater than by air [27]. In addition, cryochamber and sauna are used in different manners than the other methods presented above (e.g., exposure to extremely low and very high temperatures, respectively, application during only short durations with a cryochamber). For these reasons, studies using cryotherapy chambers or sauna were not included in this review. Passive recovery (sitting at room temperature) was generally used as a control condition, while other alternative control recovery methods were sometimes proposed, such as thermoneutral water immersion (TWI) and active recovery. Water temperature of $\sim 35^{\circ} \mathrm{C}$ is usually considered as thermoneutral because it does not change core temperature during prolonged immersion. Lower water temperatures $\left(28-34{ }^{\circ} \mathrm{C}\right)$ were also considered as thermoneutral as they unlikely to cause reduced body temperature during moderate exposure [28]. It is important to highlight that most studies included in this review employed young healthy male subjects who were recreationally active or well-trained. Therefore, the described cooling/heating effects (or absence of effect) should be interpreted with caution when other populations are considered.

\section{Resistance Exercise}

Numerous studies which evaluated the effects of cooling or heating have assessed maximal voluntary isometric contraction (MVIC) torque [20, 25, 29-33], 1 repetition maximum (1-RM) strength $[34,35]$, or electrically evoked muscle force [20], as primary functional outcome measures (Table 1). Other studies have employed various jump tests to assess the post-exercise recovery of power generation which is relevant to fast movements in sports [29]. Several studies have also determined muscle fatigue resistance measured as the total work performed over a resistance exercise session [29, 30, 32, 34, 36-39].

\section{Early Recovery Phase (5 min to $6 \mathrm{~h}$ )}

Four studies have examined the effects of CWI on the recovery of neuromuscular function in the immediate post-recovery period up to $6 \mathrm{~h}$ following resistance exercise $[20,29,30,33]$. In the immediate (5-40 min) post-recovery period, knee extension MVIC torque was recovered following $10 \mathrm{~min} \mathrm{CWI}$ at $10{ }^{\circ} \mathrm{C}$, whereas it remained lower than pre-exercise values in the control condition (active recovery) [30]. At the $2 \mathrm{~h}$ post-exercise recovery period, Pointon and colleagues showed 


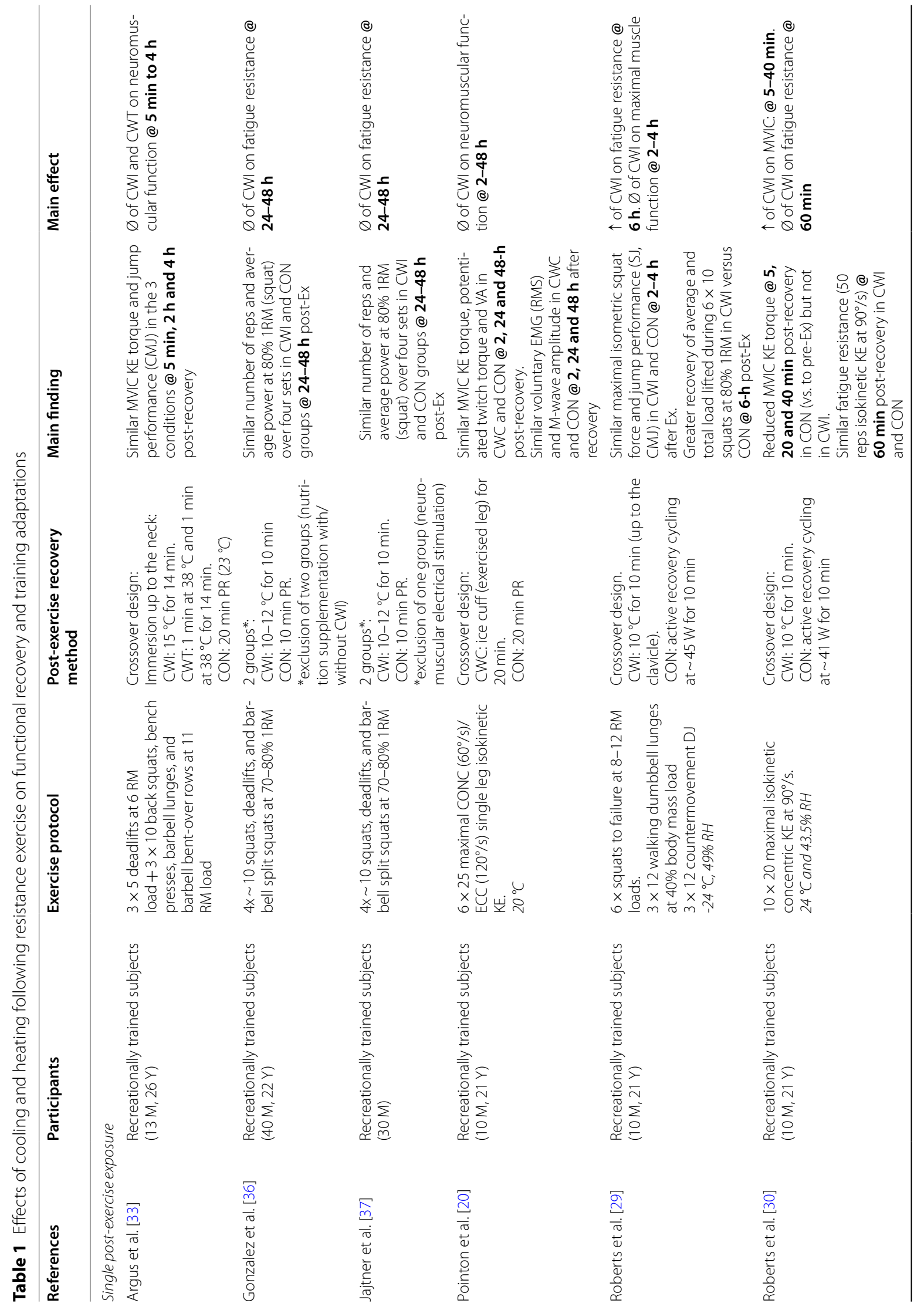




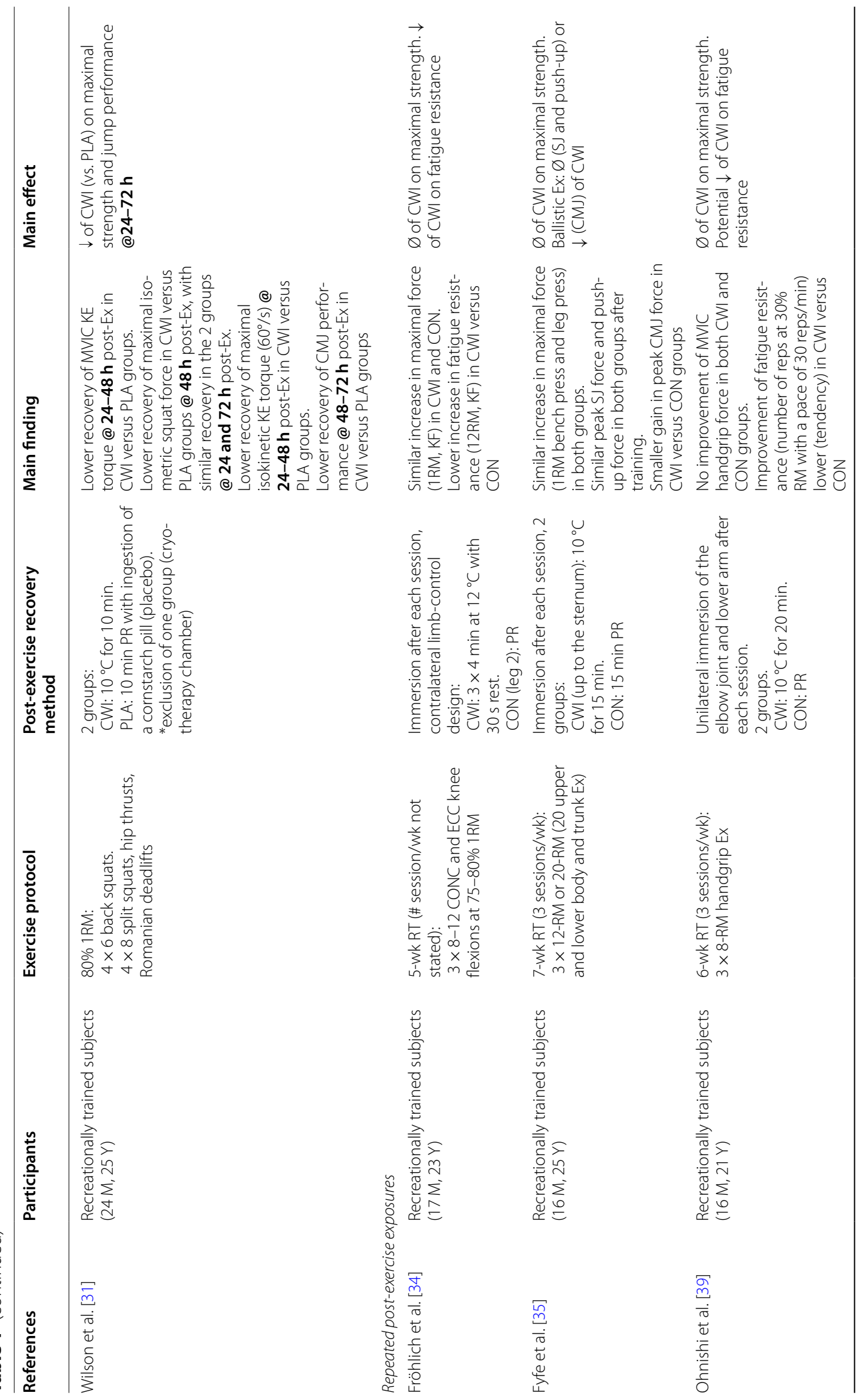




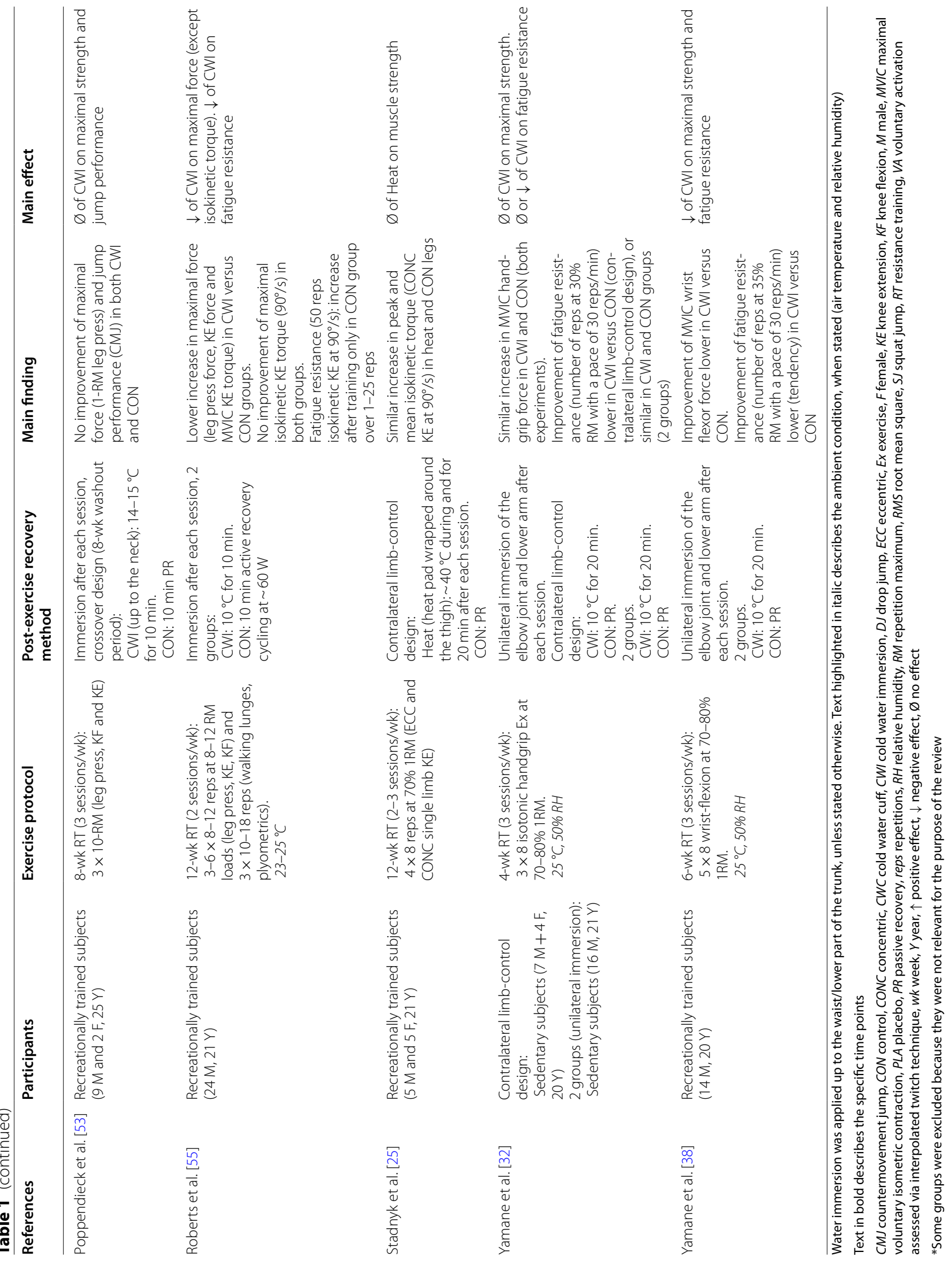




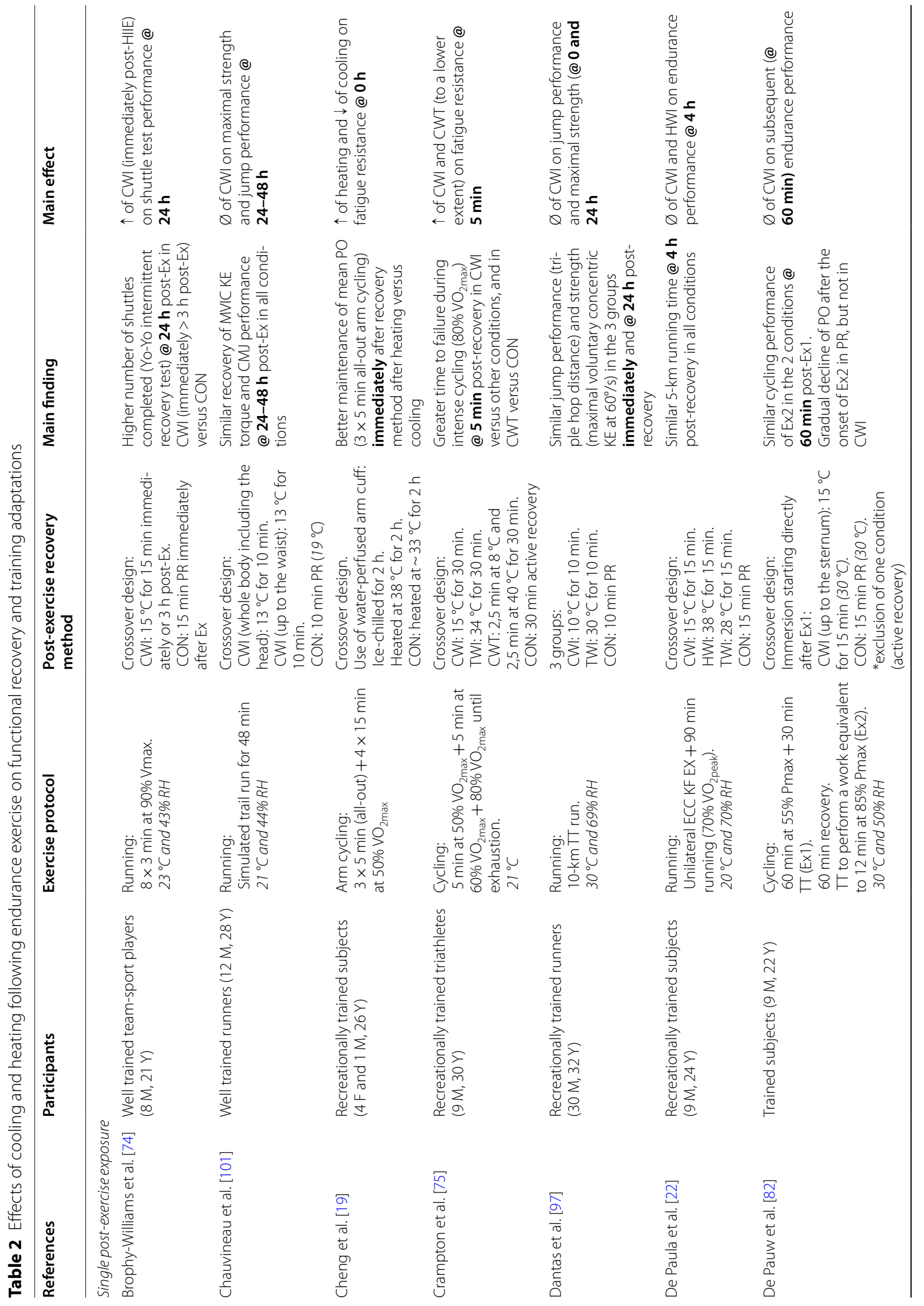




\begin{tabular}{|c|c|c|c|c|c|c|c|c|}
\hline & 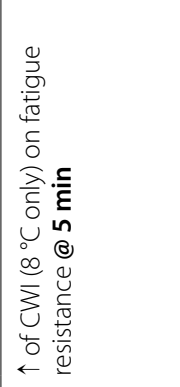 & 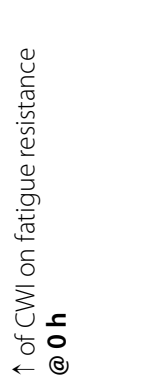 & 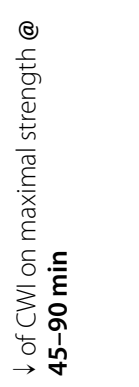 & 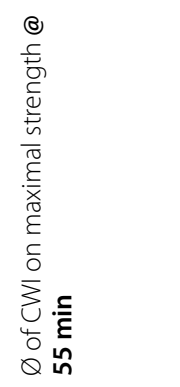 & 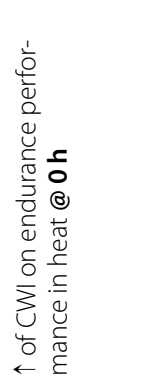 & 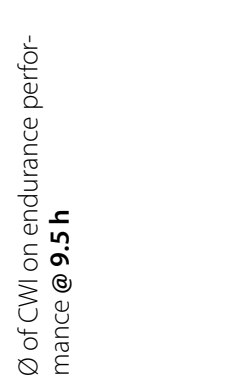 & 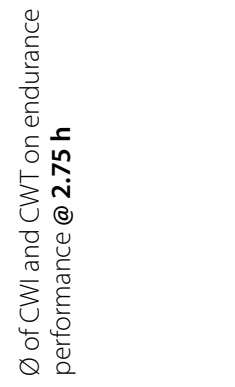 & 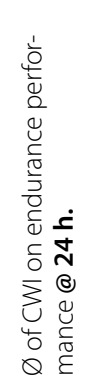 \\
\hline & 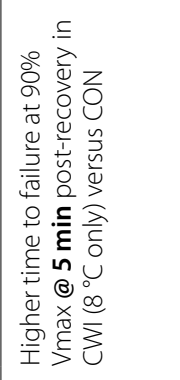 & 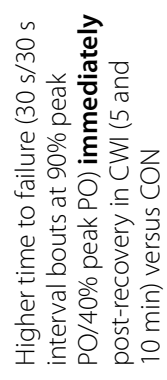 & 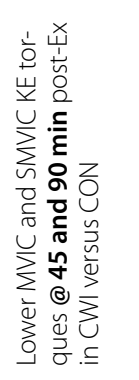 & 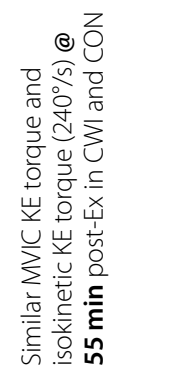 & 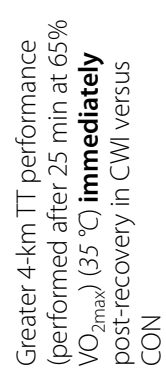 & 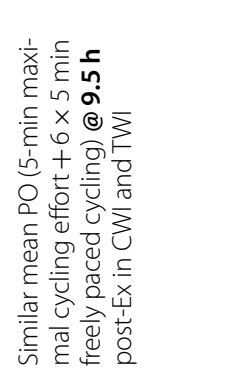 & 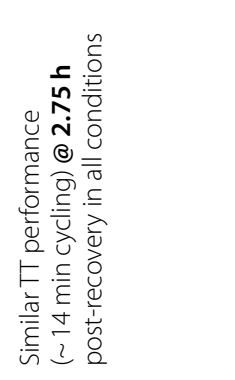 & 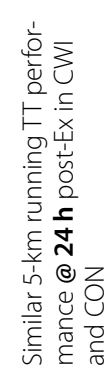 \\
\hline 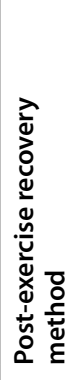 & 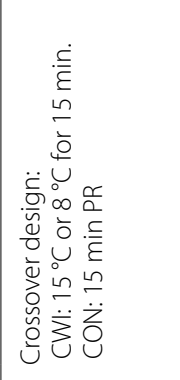 & 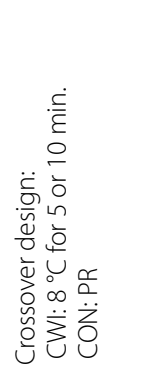 & 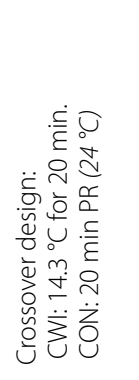 & 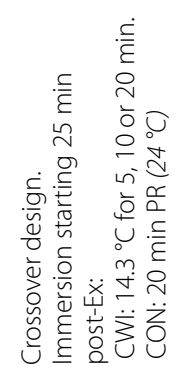 & 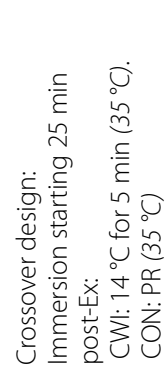 & 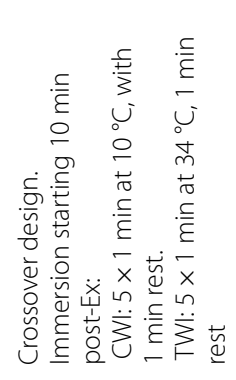 & 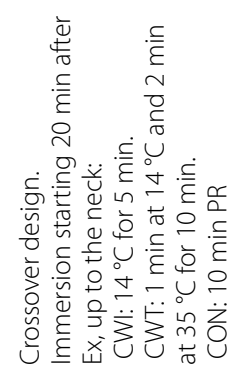 & 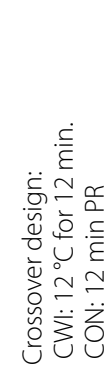 \\
\hline & 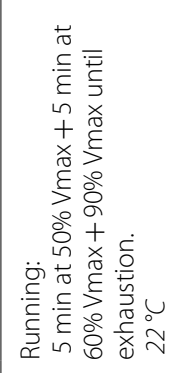 & 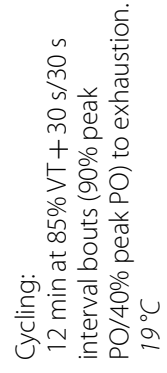 & 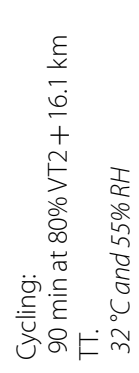 & 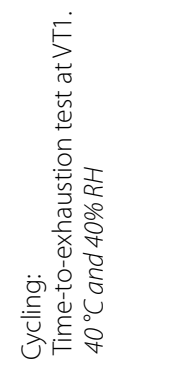 & 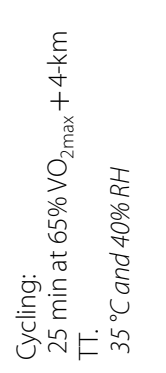 & 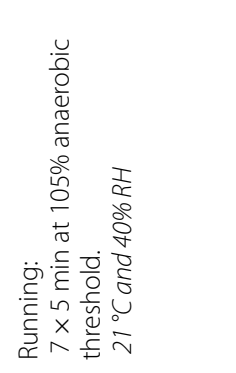 & 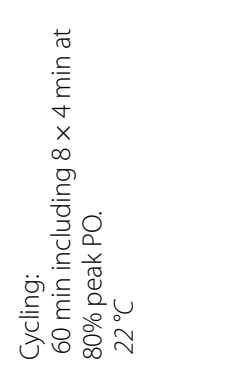 & 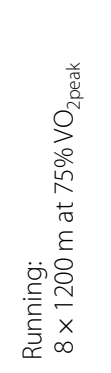 \\
\hline & 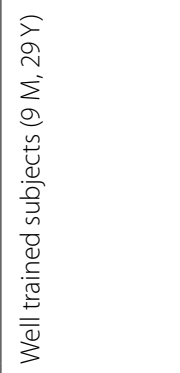 & 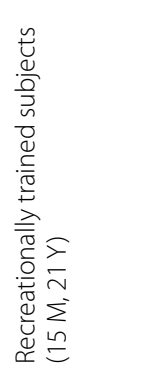 & 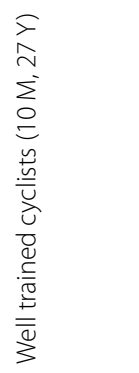 & 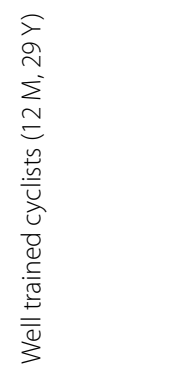 & 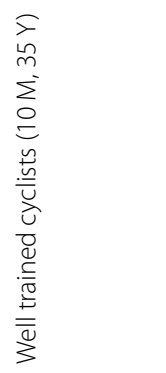 & 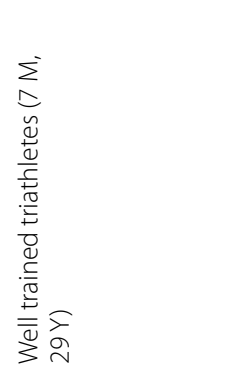 & 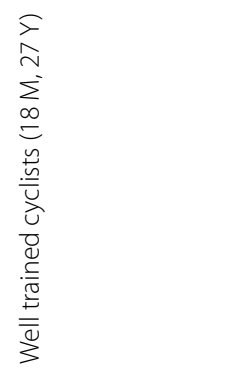 & 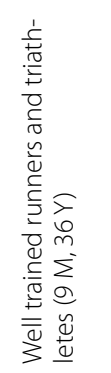 \\
\hline 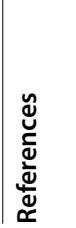 & 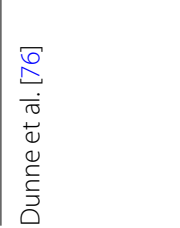 & 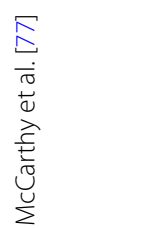 & 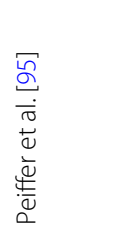 & 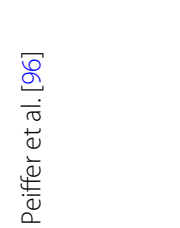 & 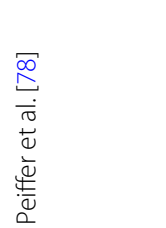 & 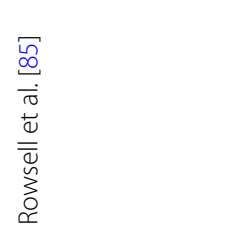 & 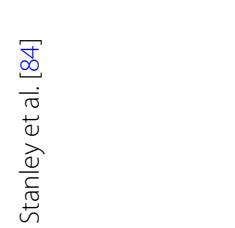 & 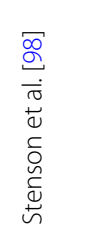 \\
\hline
\end{tabular}




\begin{tabular}{|c|c|c|c|c|c|}
\hline & 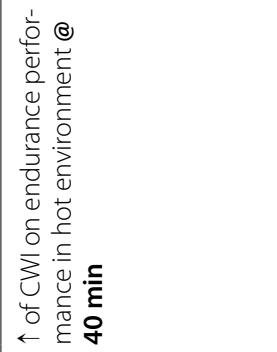 & 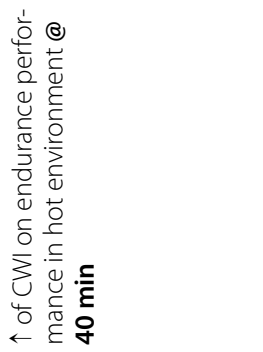 & 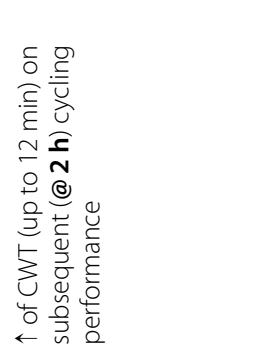 & 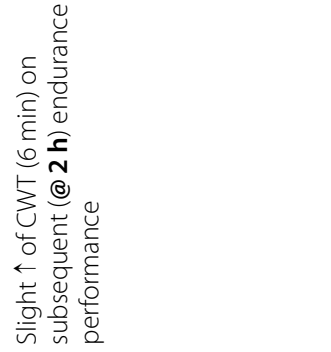 & 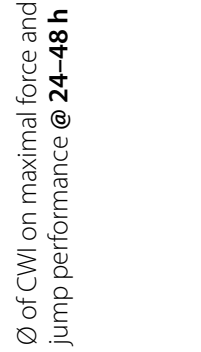 \\
\hline & 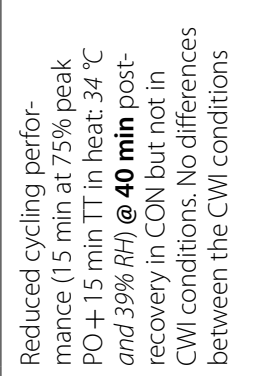 & 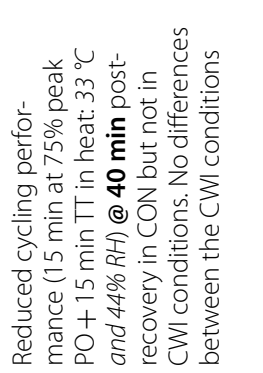 & 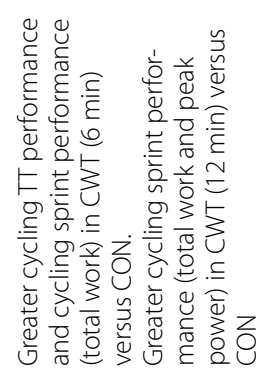 & 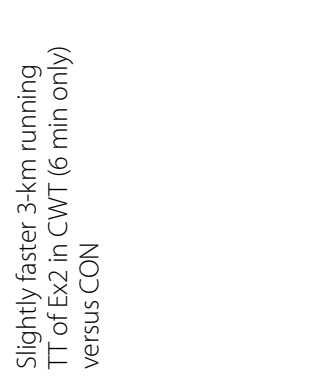 & 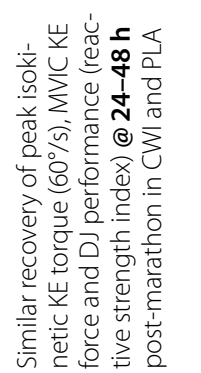 \\
\hline 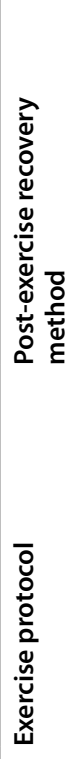 & 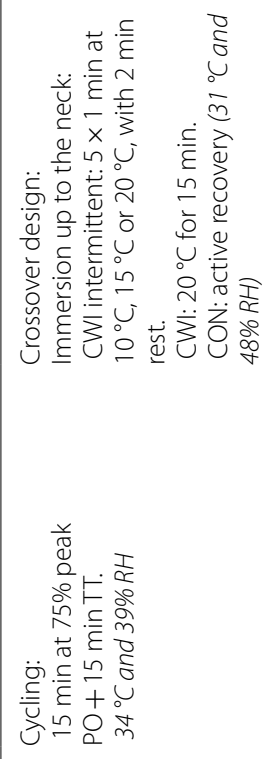 & 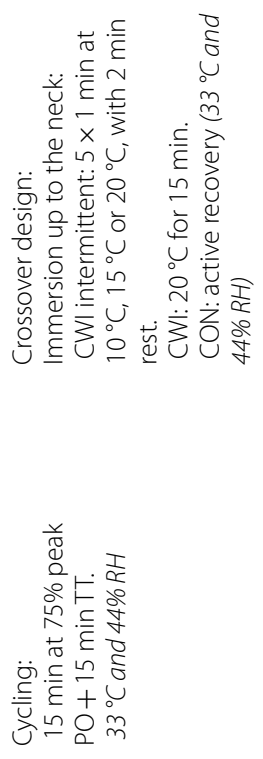 & 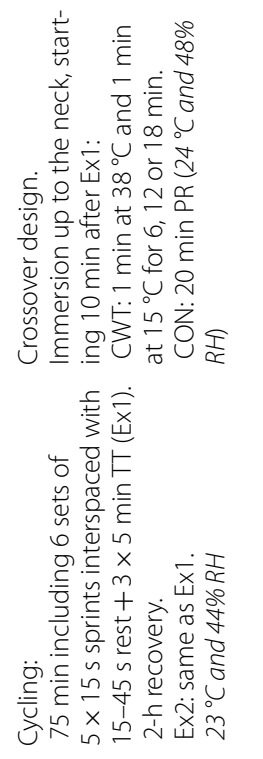 & 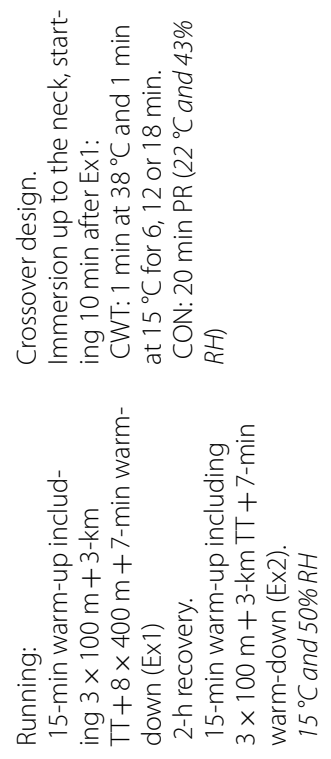 & 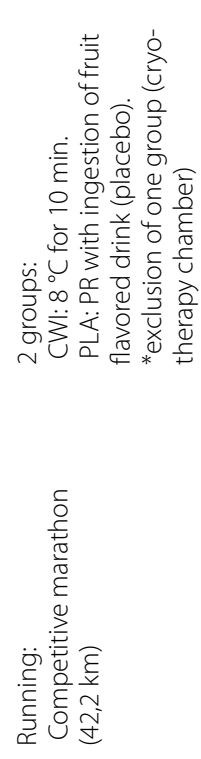 \\
\hline & 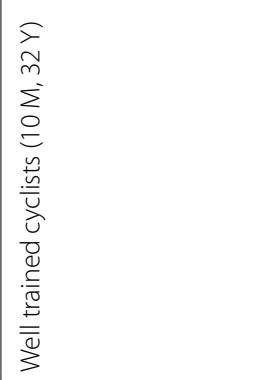 & 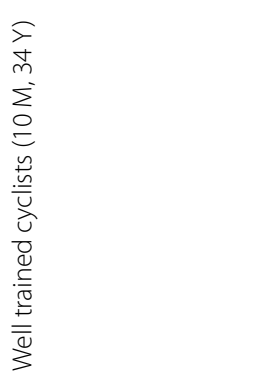 & 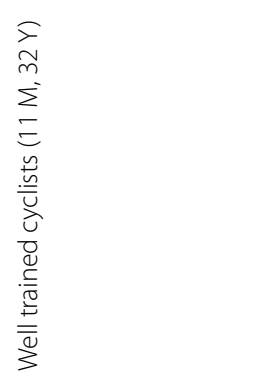 & 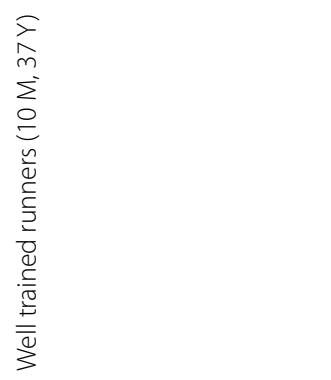 & 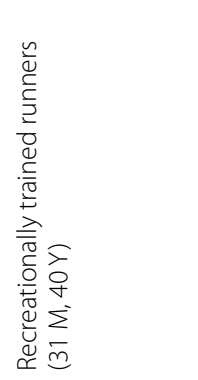 \\
\hline & 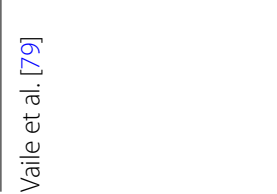 & 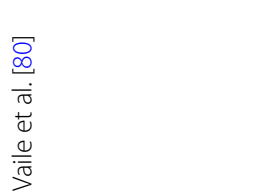 & 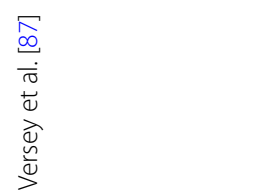 & 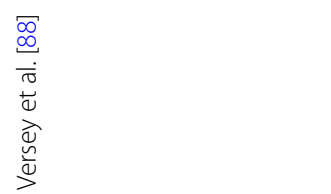 & 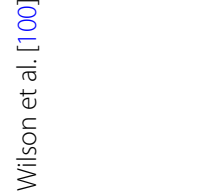 \\
\hline
\end{tabular}




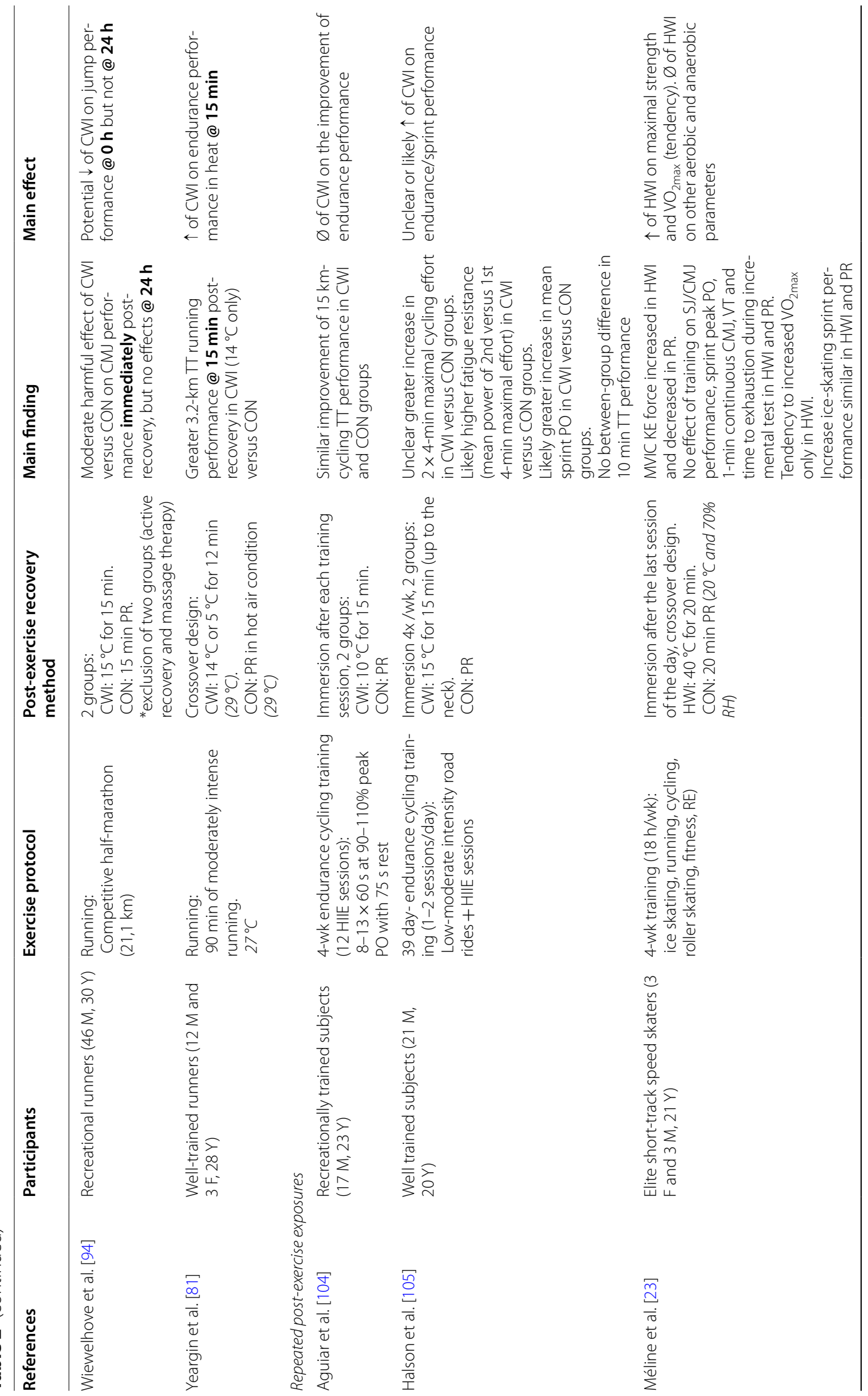




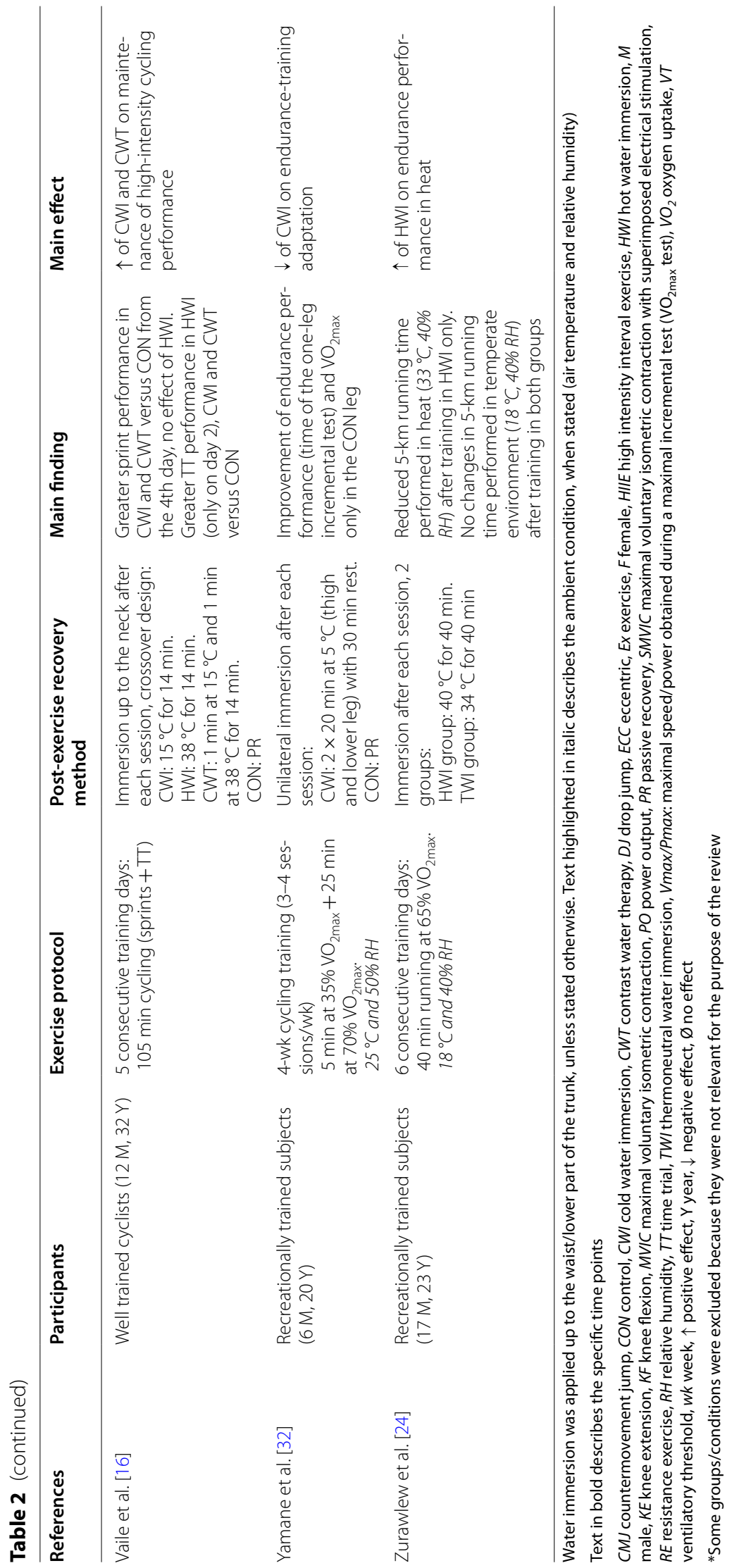




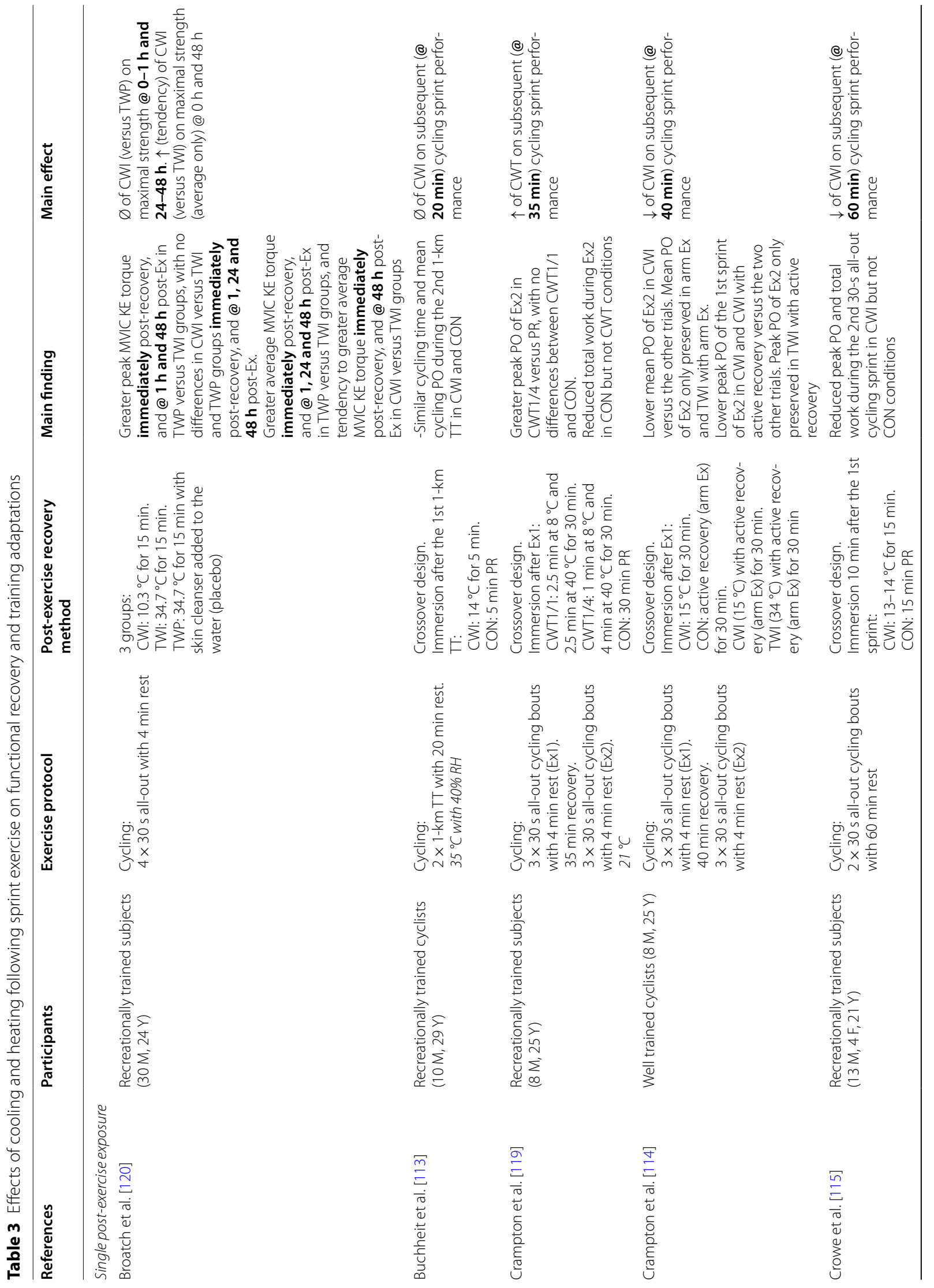




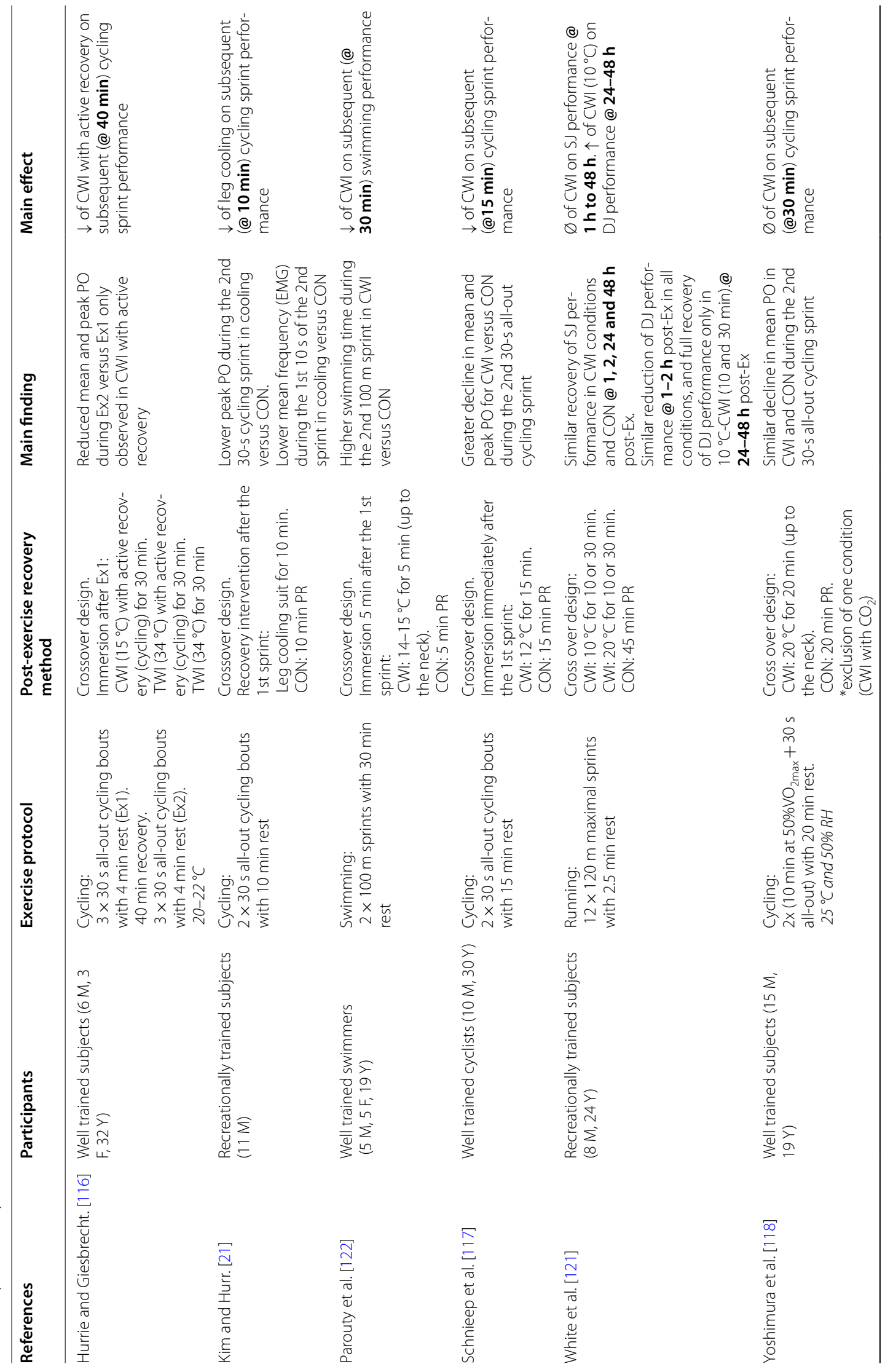




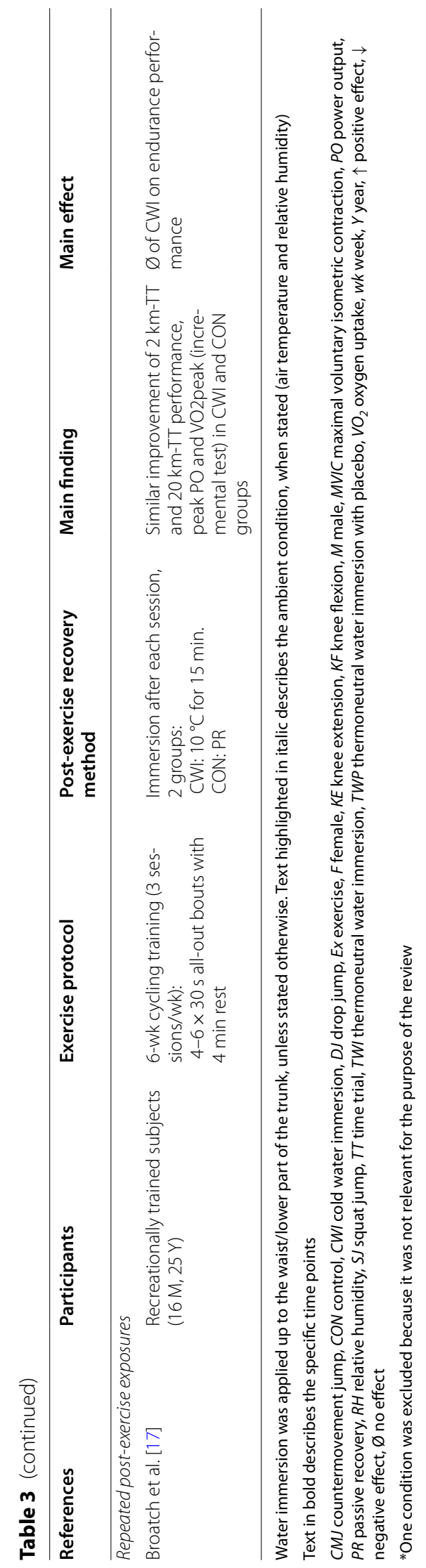


that the recovery of knee extension MVIC torque and voluntary activation were similar between the control rested condition and the cooling condition (ice cuff covering the entire exercised leg for 20 min immediately post-exercise) [20]. Another study by Roberts et al. (2014) assessed the recovery of neuromuscular function in the 2-6 h post-exercise recovery period [29]. Maximal muscle function determined by jump performance or peak isometric strength was not different in the CWI versus control conditions. However, fatigue resistance determined as average and total load lifted during 6 sets $\times 10$ squats at $80 \% 1-\mathrm{RM}$ was increased in the CWI versus control conditions at $6 \mathrm{~h}$ post-exercise. Conversely, a subsequent paper by Roberts and colleagues showed that fatigue resistance determined as total work performed during 50 repetitions of single legged isokinetic knee extensions at $90 \% \mathrm{~s}$ was similar in the CWI versus control conditions at $1 \mathrm{~h}$ post-exercise [30]. Similarly, no benefits of CWI were evident for the recovery of MVIC and jump performance within $4.25 \mathrm{~h}$ after a resistance exercise session [33].

One proposed mechanism by which CWI may increase the recovery of strength during the 5-40 $\mathrm{min}$ post-recovery period is by reducing pain perception through inhibiting the metabolite sensitive III and IV muscle afferents [40], which are sensitive to increases in [lactate], $\left[\mathrm{H}^{+}\right]$, and high [ATP] $[41,42]$. Although the accumulation of pain-inducing metabolites such as lactate is relatively high during resistance exercise including multiple sets performed at maximal intensity $[43,44]$, the majority of lactate removal occurs within 15 min post-exercise [45], arguing that this mechanism of pain inhibition will only explain the short-term enhancement of muscle function recovery mediated by CWI. Another hypothesis is that the acute effects of CWI on muscle function relate directly to temperature-dependent effects on excitation-contraction coupling processes. Indeed, it has been shown in the non-fatigued state that local muscle cooling induces a leftward shift in the force-frequency relationship with the force enhancement most evident at low compared with high activation frequencies [46, 47], which is likely caused by both a slowing of sarcoendoplasmic reticulum calcium transport ATPase (SERCA) pumps and cross-bridge kinetics augmenting pulse-induced force fusion $[47,48]$. However, the temperature reduction following $10 \mathrm{~min} \mathrm{CWI}$ at $10{ }^{\circ} \mathrm{C}$ in the vastus lateralis muscle $(1 \mathrm{~cm}$ depth $)$ is variable ranging from only $1-2{ }^{\circ} \mathrm{C}$ to as much as $12{ }^{\circ} \mathrm{C}$ among subjects [29], suggesting a modest role of temperature on altered excitation-contraction coupling. Therefore, any benefits of acute cooling on enhanced muscle force generation appear to be modest.

\section{Later Recovery Phase (24-72 h)}

In the post-exercise recovery period lasting $24-72 \mathrm{~h}$, the effects of immediate post-exercise muscle cooling on muscle function are likely to have disappeared as the muscle recovers to its physiological temperature. For instance, Wilson et al. (2019) showed that following a lower body resistance exercise session, the recovery of knee extension MVIC torque, maximal isometric squat strength, and $60 \% \mathrm{~s}$ maximal isokinetic knee extension torque $24-72 \mathrm{~h}$ following $10 \mathrm{~min} \mathrm{CWI}$ at $10{ }^{\circ} \mathrm{C}$ were similar or worse than in the control placebo condition [31]. In addition, Pointon et al. (2011), who performed $20 \mathrm{~min}$ cooling using an ice cuff following single leg isokinetic knee extensions, showed no differences in sarcolemmal membrane excitability (measured by M-wave amplitudes from surface EMG), submaximal torque (potentiated twitch torque) or MVIC torque 24-48 h post-exercise, compared with the control condition [20]. These two studies suggest that muscle contractile function is either impaired or not affected by CWI when assessed at 24-72 $\mathrm{h}$ following resistance exercise.

Fatigue resistance has also been assessed in the 24-48 h period following a single session of resistance exercise and subsequent $10 \mathrm{~min} \mathrm{CWI}$ at $10-12{ }^{\circ} \mathrm{C}[36,37]$. Fatigue resistance during resistance exercise is primarily dictated by intramuscular factors [49]. Muscle metabolite accumulation during this high-intensity type of brief duration exercise leads to rapid force loss from increased inorganic phosphate $\left(\mathrm{P}_{\mathrm{i}}\right)$ and hydrogen ion $\left(\mathrm{H}^{+}\right)$affecting predominately sarcoplasmic reticulum $(\mathrm{SR}) \mathrm{Ca}^{2+}$ release, myofibrillar $\mathrm{Ca}^{2+}$ sensitivity, and cross-bridge force generation $[12,13,50]$. However, clearance of metabolites largely occurs within 5-10 min following fatigue induction [51, 52], arguing that any effect of acute CWI on metabolite clearance will have no consequence on fatigue resistance during a subsequent exercise test performed 24-48 $\mathrm{h}$ later. Indeed, in the two studies that previously assessed fatigue resistance at 24-48 h following a single resistance exercise session, no difference in fatigue resistance was determined between the CWI versus control groups based on the total number of squat repetitions at $80 \%$ 1-RM, and average squat power per repetition over four sets of exercise [36, 37]. In summary, CWI following resistance exercise does not affect fatigue resistance after $24-48 \mathrm{~h}$.

\section{Repeated Post-exercise Cooling/Heating (4-12 Weeks of Training)}

Several studies have investigated whether repeated use of CWI during resistance training intervention affects muscle strength improvements (Table 1). In the shorter 4-8week training period, six studies performed resistance exercise involving wrist flexion or handgrip [32, 38, 39], 
knee flexion [34], or a combination of leg exercises [53] or upper and lower body exercises [35]. These exercises were followed immediately by limb [32, 34, 38, 39] or whole body CWI $[35,53]$ lasting $12-20 \mathrm{~min}$ in $10-14{ }^{\circ} \mathrm{C}$ water. Compared with the control condition, CWI generally showed no effect in altering maximal strength or power gains across these studies, except in one study [38]. No improvement of maximal strength was observed after training in some of the aforementioned studies for both the CWI and control groups/conditions [39, 53], which may have erased potential negative effects of cooling on force development. Neural adaptation is the main factor responsible for the gains in strength in the first 8 weeks of resistance training [54]. Although it remains to be investigated, neural adaptation to resistance training may not be affected by CWI, which could explain the absence of any effect of CWI on strength development after a short training intervention.

When the training period was extended to 12 weeks, post-exercise CWI $\left(10 \mathrm{~min}\right.$ at $\left.10^{\circ} \mathrm{C}\right)$ blunted the increases in MVIC torque compared with the control condition (active recovery) [55]. In the same study, the CWIinduced impairment in muscle strength gains appeared consistent with the findings of reduced muscle hypertrophy, especially in type II muscle fibers, and reduced activation of anabolic signaling. CWI $\left(15^{\circ} \mathrm{C}\right.$ for $\left.15 \mathrm{~min}\right)$ blunted testosterone response after a bout of resistance exercise [56] and CWI $\left(8{ }^{\circ} \mathrm{C}\right.$ for $\left.20 \mathrm{~min}\right)$ applied after every resistance exercise session decreased daily muscle protein synthesis rates over a 2-week training period [57]. These findings are in line with chronic impairments in the muscle hypertrophic response observed previously [55]. While muscle protein turnover is dictated by both synthesis and breakdown processes, CWI does not seem to affect muscle protein breakdown [35].

With regard to fatigue resistance and the use of CWI over a 4-12-week resistance training period [32, 34, 38, $39,55]$, the results have consistently shown a blunted muscle fatigue resistance with CWI compared with the control condition. Muscle fatigue resistance adaptations following high-intensity exercise could be triggered by reactive oxygen and nitrogen species (RONS) induced adaptations [58, 59], whereby abolishing the exerciseinduced increase in muscle RONS generation with antioxidant supplementation blunted long-term endurance training adaptations [60-64]. RONS generation remains elevated in the recovery period after exercise [65] and CWI employed in the immediate post-exercise recovery period may diminish RONS production [66]. Thus, it could be speculated that cooling-induced reduction in RONS generation during the recovery phase might blunt fatigue resistance adaptation during resistance training. However, as presented in the next section, there is no clear evidence that post-exercise CWI impairs the development of endurance performance, suggesting that RONS-independent mechanisms are responsible for CWI-mediated reduction of fatigue resistance adaptation.

Given the detrimental effect of CWI on resistance training adaptations, a natural progression has been the investigation of HWI as a recovery modality on strength adaptations following resistance training. In a recent 12-week resistance training study, a heat pad $\left(\sim 40{ }^{\circ} \mathrm{C}\right)$ was wrapped around one thigh during the knee extension exercise session as well as during the 20 -min post-exercise recovery period of every resistance training session [25]. These authors showed that the training-induced increases in knee extension isokinetic torque $\left(90^{\circ} / \mathrm{s}\right)$ were not affected by heating compared to the contralateral untreated leg. This is consistent with the absence of effect of HWI $\left(20 \mathrm{~min}\right.$ at $\left.46{ }^{\circ} \mathrm{C}\right)$ on muscle protein synthesis rates after a resistance exercise session, compared with control condition [67]. The above studies suggest that short-term muscle heating during/after resistance training sessions might not provide an additive stimulus for improving long-term muscle strength adaptations. Compared with CWI which has a long-lasting muscle cooling effect that can persist for a few hours after immersion [68, 69], muscle temperature returns to pre-exercise values within 30 min after HWI [67]. Different results might be observed when prolonged periods of post-exercise HWI are applied during a resistance training intervention, due to the extended time of high muscle temperature after exercise. Indeed, some human studies indicate that prolonged passive heating applied on the thigh could induce a slight skeletal muscle hypertrophy (3-6\% increase in muscle cross-sectional area) and gain in muscle strength ( $6 \%$ increase in MVIC of knee extensors) without exercise training (heat-and-steam-generating sheet applied $8 \mathrm{~h} /$ day, four times/week for 10 weeks) [70] or could limit skeletal muscle atrophy associated with immobilization ( $2 \mathrm{~h}$ daily treatment with pulsed shortwave diathermy for 10 days) [71]. A recent study also found that 90-min passive heating repeated over 8 weeks (unilateral thigh heating with $\sim 52{ }^{\circ} \mathrm{C}$ water-circulating garments, 5 days/week) slightly increased maximal isokinetic knee extension torque (5\%) [72]. Future studies should investigate whether prolonged post-exercise muscle heating is effective in improving resistance training-associated adaptations.

\section{Summary}

- Early recovery phase (5 min to $6 \mathrm{~h}$ ): possible increase in maximal strength recovery following CWI between 5-40 min post-exercise, but not at later 
recovery timepoints; possible positive effect of CWI on fatigue resistance ( $1 \mathrm{~h}$ post-recovery to $6 \mathrm{~h}$ postexercise).

- Later recovery phase (24-72 h): no effect or negative effect of CWI on muscle strength recovery (24-48 h); no effect of CWI on fatigue resistance (24-48 h).

- Post-exercise recovery on chronic resistance training adaptations (4-12 weeks): no effect (4-8 weeks) or negative effect (12 weeks) of CWI on muscle strength gains; no effect of local heating on muscle strength gains; negative effect of CWI on muscle fatigue resistance.

\section{Endurance Exercise}

Endurance exercise results in numerous physiological perturbations including metabolite accumulation, hyperthermia, dehydration and glycogen depletion, which ultimately lead to fatigue and reduced performance [73]. In addition, several physiological changes are observed following endurance training intervention, such as cardiovascular and skeletal muscle adaptations [73]. Numerous studies investigated the effect of post-exercise cooling, heating, or CWT on the recovery of endurance performance, while other studies employed various neuromuscular tests to assess the recovery of muscle strength (e.g., MVIC, isokinetic force) and explosiveness (jump and sprint performances). Finally, application of post-exercise cooling or heating during regular endurance training was proposed to influence physiological adaptations and endurance performance. A summary of these studies is presented in Table 2.

\section{Early Recovery Phase (Immediate to $9.5 \mathrm{~h}$ )}

Post-exercise CWI, compared with control condition, could enhance recovery of endurance performance and fatigue resistance in the immediate period (0 to $40 \mathrm{~min}$ ) following recovery intervention [74-81]. Crampton et al. (2013) observed that the time to exhaustion during cycling $\left(80 \% \mathrm{VO}_{2 \max }\right)$ starting 5 min after recovery intervention was longer in the CWI $\left(15{ }^{\circ} \mathrm{C}\right.$ for $\left.30 \mathrm{~min}\right)$ than the other recovery conditions (active recovery, CWT and TWI) [75]. A longer time to exhaustion was also observed during intense running $\left(\sim 90 \% \mathrm{VO}_{2 \max }\right)$ in the CWI condition $\left(8{ }^{\circ} \mathrm{C}\right.$ for $\left.15 \mathrm{~min}\right)$ than passive recovery, while no differences were found with warmer water $\left(15{ }^{\circ} \mathrm{C}\right.$ for $\left.15 \mathrm{~min}\right)$ [76]. This positive effect of CWI was generally observed when exercise was performed in thermoneutral $\left(\sim 20^{\circ} \mathrm{C}\right)[77]$ or in hot environments [78-80]. In contrast, CWI $\left(15{ }^{\circ} \mathrm{C}\right.$ for $\left.15 \mathrm{~min}\right)$ performed after a strenuous endurance session in the heat $\left(30{ }^{\circ} \mathrm{C}\right.$ and $50 \%$ relative humidity) did not significantly improve subsequent endurance performance (lowest cycling time to perform a work equivalent to $12 \mathrm{~min}$ at $85 \%$ Pmax) compared with passive recovery, when assessed 45 min after recovery intervention [82]. Core temperature increases during prolonged and intense lower limb endurance exercise executed in thermoneutral conditions, and this increase is accentuated in hot conditions [83]. CWI can accelerate the post-exercise reduction in core temperature, allowing maintenance of a cooler core body temperature during the subsequent endurance session [78-80, 82]. Thus, CWI could improve the heat storage capacity and reduce the thermoregulatory demand for heat dissipation, thereby alleviating cardiovascular strain, enhancing blood flow redistribution to active muscle, reducing perceived effort, and limiting central fatigue and dehydration [6].

In contrast, post-exercise CWI $\left(14-15^{\circ} \mathrm{C}\right.$ for $\left.5-15 \mathrm{~min}\right)$ does not improve the performance of a subsequent endurance exercise performed in thermoneutral conditions when the period between the two sessions is more prolonged ( 3 to $9.5 \mathrm{~h}$ ) [22, 84, 85], despite an improved perceived recovery [84]. Rectal temperature measured during a $5-\mathrm{km}$ running time trial performed $\sim 4 \mathrm{~h}$ after an initial exhaustive endurance exercise was identical between CWI and passive recovery trials [22], indicating that thermal stress during the second session was certainly similar in both conditions. To conclude, although numerous factors need to be considered (e.g., duration and intensity of exercise, ambient conditions, CWI protocol, etc.), post-exercise CWI only improves subsequent endurance performance when the period between the two sessions is short $(<1 \mathrm{~h})$, and this is possibly due to the lowered heat stress applied on the body during the second exercise bout. In addition, it remains to be investigated whether the beneficial effect of CWI on subsequent endurance performance in the heat persists for longer periods (i.e., $3-6 \mathrm{~h}$ ).

We have recently shown in recreationally active subjects that prolonged local post-exercise cooling $(2 \mathrm{~h}$ with ice-chilled water-perfused arms) negatively affects fatigue resistance during a subsequent high-intensity arm-cycling session $(3 \times 5 \mathrm{~min}$ all-out bouts $)$ performed $\sim 10 \mathrm{~min}$ after cooling [19]. Core temperature was $\sim 36.5{ }^{\circ} \mathrm{C}$ during the 2 h-recovery period and was not reduced by local cooling, suggesting that cooling did not change thermal stress during subsequent exercise. In this study, cooling induced a severe drop of the temperature in triceps brachii muscle during the 2-h-recovery period $\left(\sim 17{ }^{\circ} \mathrm{C}\right.$ on average at $1.5 \mathrm{~cm}$ depth), while the drop in vastus lateralis muscle temperature after conventional CWI protocols is generally much lower $\left(\sim 3-5{ }^{\circ} \mathrm{C}\right.$ on average at $1-3 \mathrm{~cm}$ depth) $[29,69,86]$. Although not investigated by Cheng et al. [19] ${ }_{2}$ severe local cooling may have induced arterial vasoconstriction in the upper 
limbs, thereby potentially reducing muscle blood flow, oxygen and nutrient delivery, and metabolite clearance during subsequent exercise.

In contrast, prolonged local heating $\left(38^{\circ} \mathrm{C}\right.$ heated arm cuff for $2 \mathrm{~h}$ ) improved fatigue resistance during $3 \times 5 \mathrm{~min}$ all-out arm-cycling bouts performed in thermoneutral conditions $\sim 10 \mathrm{~min}$ after heating [19]. Another study found that short HWI $\left(38{ }^{\circ} \mathrm{C}\right.$ for $\left.15 \mathrm{~min}\right)$ did not affect $5-\mathrm{km}$ running performance (compared with passive recovery) in thermoneutral conditions $\sim 4 \mathrm{~h}$ following the initial bout [22]. These controversial findings could result from the duration and form of local heating, and from the exercise test performed. Although it remains to be investigated, prolonged post-exercise heating may impair subsequent endurance performance executed in hot ambient conditions due to the reduced heat storage capacity and increased demand for heat dissipation, which consequently would exacerbate thermal and cardiovascular strains.

Four studies investigated the impact of CWT executed after a strenuous endurance session on the subsequent performance $[75,84,87,88]$. Three of these four studies observed a beneficial effect of post-exercise CWT on subsequent endurance performance executed up to $2 \mathrm{~h}$ after the initial exercise session $[75,87,88]$, while no effect was found when the period between the two sessions was more prolonged ( $3 \mathrm{~h} 15 \mathrm{~min}$ ) [84]. In addition, short exposure to CWT (6 min) was more beneficial than longer exposure (18 $\mathrm{min})$, at least when subsequent exercise is performed $2 \mathrm{~h}$ following the first session $[87,88]$. Finally, CWT $\left(8^{\circ} \mathrm{C} / 40{ }^{\circ} \mathrm{C}\right.$ for $\left.30 \mathrm{~min}\right)$ was not as effective as $\mathrm{CWI}\left(15^{\circ} \mathrm{C}\right.$ for $\left.15 \mathrm{~min}\right)$ in improving the time to failure at $80 \% \mathrm{VO}_{2 \max }$ when exercise was performed $5 \mathrm{~min}$ post-recovery [75].

Ex vivo experiments showed that exposing mouse intact single muscle fibers to $26^{\circ} \mathrm{C}$ for $1 \mathrm{~h}$ directly after a fatiguing protocol impaired subsequent endurance performance (repeated tetanic contractions) compared with $36{ }^{\circ} \mathrm{C}$, confirming the temperature-dependent effect on fatigue resistance [19]. This finding was associated with a slower glycogen repletion at $26{ }^{\circ} \mathrm{C}$ than $36^{\circ} \mathrm{C}$ in whole muscle. Similarly, 4-h exposure to local heating (heat pack) promoted glycogen resynthesis in the human vastus lateralis muscle after cycling [89], while the opposite result was observed after a 4-h intermittent exposure to ice cooling (plastic bags) [90]. In contrast, short exposure to CWI $\left(10 \mathrm{~min}\right.$ at $\left.8{ }^{\circ} \mathrm{C}\right)$ did not impair muscle glycogen repletion [86]. Prolonged local heating may influence muscle glycogen repletion by modulating glucose delivery and muscle glucose uptake, and by affecting the activity of glycogen synthase and phosphorylase [91-93]. Altogether, prolonged local cooling or heating seems to influence muscle glycogen resynthesis following exhausting endurance exercise. This could have a direct impact on endurance exercise capacity when the subsequent exhausting endurance session is highly dependent on muscle glycogen as an energy substrate, and the exercise is performed within a few hours ( $4-8 \mathrm{~h}$ ) following the first session.

There are limited data available on the effect of postendurance exercise cooling on early recovery of neuromuscular function. Countermovement jump (CMJ) performance and muscle strength (MVIC of knee extensors) were impaired during the immediate period following post-exercise CWI $\left(14-15{ }^{\circ} \mathrm{C}\right.$ for $15-20$ min vs. passive recovery) [94, 95]. However, no effect of CWI was observed on MVIC [96], isokinetic force [96, 97] and jump performance [97] in the immediate phase following recovery intervention when the initial endurance exercise was performed in the heat $\left(30-40{ }^{\circ} \mathrm{C}\right)$. At the single fiber level in mice, $0.5-2 \mathrm{~h}$ cooling was shown to impair the recovery of contractile force after low-intensity fatiguing stimulation, especially at submaximal levels of activation, and this was attributed to impaired SR $\mathrm{Ca}^{2+}$ release [19]. A limited number of ex vivo studies from mouse skeletal muscle showed a beneficial effect of heating on submaximal force recovery, which was associated with enhanced muscle glycogen re-synthesis and faster restoration of $\mathrm{SR} \mathrm{Ca}^{2+}$ release $[19,91,93]$. To date, the effect of heating on early recovery of human neuromuscular function remains to be investigated.

\section{Later Recovery Phase (24-72 h)}

Post-exercise CWI $\left(10-12{ }^{\circ} \mathrm{C}\right.$ for $\left.5-10 \mathrm{~min}\right)$ did not improve $5-\mathrm{km}$ running performance when the betweensession recovery period was $24 \mathrm{~h}$ [98]. However, running performance (number of shuttles completed during a Yo-Yo intermittent recovery test) performed $24 \mathrm{~h}$ after interval exercise $(8 \times 3 \mathrm{~min})$ was slightly improved when the initial exercise session was followed by CWI $\left(15^{\circ} \mathrm{C}\right.$ for $15 \mathrm{~min}$ ) compared with passive recovery [74]. The effect of post-exercise local heating on endurance performance during the later recovery phase remains to be investigated. As discussed in "Early Recovery Phase (Immediate to $9.5 \mathrm{~h}$ )" section, prolonged local heating and cooling following exhausting endurance exercise seems to influence muscle glycogen repletion, and this may have a direct impact on the subsequent performance when endurance exercise is performed $4-8 \mathrm{~h}$ after the initial session. Since muscle glycogen stores are usually fully replenished within $24-48 \mathrm{~h}$ after prolonged endurance exercise when carbohydrate is provided adequately [99], local cooling or heating following glycogen-depleting exercise would unlikely affect performance of endurance exercise bouts performed 1-2 days after the initial bout. 
CWI $\left(8-15{ }^{\circ} \mathrm{C}\right.$ for $\left.10-15 \mathrm{~min}\right)$ did not influence the later post-exercise recovery of muscle strength (peak isokinetic torque and MVIC, 24-48 h post-exercise) and jump performance [drop jump (DJ), 24-48 h postexercise; CMJ, 24-48 h post-exercise; triple hop, $24 \mathrm{~h}$ post-exercise] [94, 97, 100, 101]. In these studies, these outcomes were only slightly impaired directly after the initial endurance session and were fully recovered within 24-48 h. Future experiments could focus on the impact of post-exercise cooling in extreme endurance activities (such as mountain ultra-marathon) where neuromuscular function is substantially impaired directly after exercise $[102,103]$ and required several days to be fully recovered [103].

\section{Repeated Post-exercise Cooling/Heating (up to 5 Weeks of Training)}

Post-exercise CWI during an aerobic training program (4 weeks) did not promote or limit the development of endurance performance [32, 104]. Moreover, postexercise CWI during an intense 39-day cycling training intervention (1-2 sessions/day) did not affect 10-min time trial performance, but magnitude-based inferences showed that CWI had an unclear greater increase in $2 \times 4$-min mean power and a likely greater increase in mean sprint power compared with passive recovery [105]. As described in recent reviews [3, 4], local cooling (CWI mostly studied) after endurance exercise is able to stimulate some molecular actors regulating muscle adaptation and angiogenesis. For instance, CWI was shown to potentiate the exercise-mediated upregulation of peroxisome proliferator-activated receptor gamma coactivator 1-alpha (PGC1A), a major regulator of mitochondrial biogenesis $[69,106,107]$. Post-exercise CWI also increased the mRNA levels of vascular endothelial growth factor $(V E G F)$, a gene promoting angiogenesis [69], a result associated with an enhanced microvascular adaptation [108]. Currently, there is no clear evidence that post-exercise CWI does potentiate the gain in endurance performance. Future research including longer training interventions would allow to draw clear conclusions about the role of CWI in augmenting endurance training adaptations.

To our knowledge, only one study investigated the influence of post-exercise heating on the development of endurance performance during a training intervention [23]. Six elite short-track speed skaters trained over a 4 -week period $\left(18 \mathrm{~h} /\right.$ week) and HWI $\left(40{ }^{\circ} \mathrm{C}\right.$ for $20 \mathrm{~min}$ ) was applied after the last session of the day. In general, HWI did not affect endurance and sprint performance compared with passive recovery. However, it had a positive effect on maximal strength (MVIC) and the tendency to increased $\mathrm{VO}_{2 \max }(P=0.053)$ in response to the training intervention was only found in the HWI condition. Except for small improvement (effect size $d \sim 0.2$ ) of half-lap time and total time during the 1.5-lap all-out ice-skating exercise in the passive recovery condition, this short training program did not significantly improve the performance of the other field tests on ice (3-lap and 7-lap all-out exercises) in these elite athletes. In addition to the small sample size, the absence of improvement or small improvements of exercise capacity after training intervention may have minimized the chance of detection of potential HWImediated benefits on enhancing sport performance in these elite short-track speed skaters.

A recent study on sedentary subjects observed that compared to the control unheated leg, 2-h local heating (pulsed shortwave diathermy) increased the phosphorylation of AMP kinase (AMPK) and extracellular signal-regulated kinase 1/2 (ERK1/2), both associated with mitochondrial biogenesis [109]. The same study showed that repeated exposures to the same heating method $(2 \mathrm{~h}$ daily for 6 consecutive days) increased PGC1A protein levels and maximal mitochondrial respiratory capacity [109]. In contrast, $1 \mathrm{~h}$ local heating of one leg (watercirculating sleeve connected to a bath circulator set at $49.5{ }^{\circ} \mathrm{C}$ ) did not affect the expression of any markers of mitochondrial biogenesis in recreationally trained individuals [110]. In addition, acute local heating (lower body heating or unilateral thigh heating with $48-52{ }^{\circ} \mathrm{C}$ watercirculating garments for $90 \mathrm{~min}$ ) increased the mRNA levels of factors associated with capillary growth [e.g., $V E G F$ and angiopoietin 2 (ANGPT2)] in skeletal muscle of recreationally active subjects [111]. Repeated exposures to local heating for 8 weeks (unilateral thigh heating with $\sim 52{ }^{\circ} \mathrm{C}$ water-circulating garments for $90 \mathrm{~min}$, 5 days/week) increased the protein content of endothelial nitric oxide synthase (eNOS) and had a positive effect on the capillarization of type-II muscle fibers compared with the control condition, while it did not affect mitochondrial content [72]. Whether prolonged post-exercise local heating could promote the development of muscle oxidative capacities, capillarization and endurance adaptations over a training intervention ( $>8$ weeks) remains to be investigated.

To date, two studies investigated the impact of repeated uses of post-exercise HWI, CWI or CWT during a short intervention period (5-6 days) on the maintenance of physical performance $[16,24]$. Daily exposure (immersion up to the neck) to $\mathrm{CWI}\left(15^{\circ} \mathrm{C}\right.$ for $\left.14 \mathrm{~min}\right)$ or CWT $\left(15^{\circ} \mathrm{C} / 38^{\circ} \mathrm{C}\right.$ for $14 \mathrm{~min}$ ) following prolonged cycling was effective in maintaining sprint cycling performance, while HWI (38 ${ }^{\circ} \mathrm{C}$ for $14 \mathrm{~min}$ ) had no effect [16]. Zurawlew et al. showed that daily $\mathrm{HWI}\left(40{ }^{\circ} \mathrm{C}\right.$ for $\left.40 \mathrm{~min}\right)$ following 40 min running $\left(65 \% \mathrm{VO}_{2 \max }\right)$ improved $5-\mathrm{km}$ running 
performance (compared to TWI at $34{ }^{\circ} \mathrm{C}$ for $40 \mathrm{~min}$ ) in hot $\left(33^{\circ} \mathrm{C}\right)$ but not temperate $\left(18{ }^{\circ} \mathrm{C}\right)$ environments [24], indicating that HWI could be relevant for improving acclimation to heat.

\section{Summary}

- Early recovery phase (immediate to $9.5 \mathrm{~h}$ ): CWI ( $\leq 30 \mathrm{~min}$ ) improves only endurance performance when the second exercise is performed $<1 \mathrm{~h}$ after the initial session. One study indicates that prolonged local cooling $(2 \mathrm{~h})$ impairs endurance performance recovery immediately after cooling, while prolonged local heating $(2 \mathrm{~h})$ is beneficial. There is no or negative effect of CWI on jump performance and maximal strength immediately after recovery intervention.

- Later recovery phase (24 to $72 \mathrm{~h}$ ): no effect of CWI on recovery of neuromuscular function and endurance performance.

- Post-exercise recovery on chronic endurance training adaptations (up to 5 weeks): no clear effect of CWI and HWI on improvement of endurance performance.

\section{Sprint Exercise}

Training including short and prolonged sprints promotes the development of peak power output (PO) and anaerobic capacity, which are required in most competitive sports. Sprint interval training can also elicit skeletal muscle and cardio-respiratory adaptations generally observed following endurance training [73, 112]. Several studies have investigated the impact of cooling [21, 113-118] and CWT [119] following one or 3-4 bouts of all-out sprint exercise on the recovery of peak PO, mean $\mathrm{PO}$ or total work during identical sprint exercise performed 15-60 min after the initial session. In addition, a few studies evaluated the effects of cooling applied after repeated sprints on the recovery of maximal strength (MVIC) [120] and jump performance [121]. Finally, the role played by post-exercise cooling during a 6-week sprint training intervention on training adaptations was recently investigated [17]. A summary of these studies is presented in Table 3. To our knowledge, the impact of post-exercise heating following sprint exercise has not yet been investigated.

\section{Early Recovery Phase (Immediate to $\mathbf{2} \mathbf{h}$ )}

The majority of the studies indicated that CWI $\left(12-15{ }^{\circ} \mathrm{C}\right.$ for 5-30 min) or local cooling (leg cooling suit) applied after 1-3 bouts of 30-s all-out cycling sprint (Wingate tests) impaired sprint performance (mean and/or peak
PO) during a subsequent exercise performed 15-60 min after the initial session $[21,114-117]$. In addition, wholebody CWI (14-15 ${ }^{\circ} \mathrm{C}$ for $\left.5 \mathrm{~min}\right)$ performed $5 \mathrm{~min}$ after a single swimming sprint $(100 \mathrm{~m})$ slightly impaired the performance of a subsequent sprint (compared with passive recovery) executed $30 \mathrm{~min}$ after the initial exercise [122]. In contrast to prolonged endurance exercise, 1-3 bouts of all-out cycling sprint performed in thermoneutral conditions induced a limited increase in core temperature $\left(0.2-0.5^{\circ} \mathrm{C}\right)[114,115]$, which was then reduced to levels below baseline $\left(36.5\right.$ vs. $\left.37.3{ }^{\circ} \mathrm{C}\right)$ after the 1 st repeated sprint bout following CWI $\left(15{ }^{\circ} \mathrm{C}\right.$ for $\left.30 \mathrm{~min}\right)$ [114]. Muscle temperature $(4 \mathrm{~cm}$ into vastus lateralis muscle) increased from $\sim 36{ }^{\circ} \mathrm{C}$ to $\sim 38{ }^{\circ} \mathrm{C}$ after 4 Wingate tests and was then reduced to $\sim 33.5^{\circ} \mathrm{C}$ directly after $\mathrm{CWI}\left(10.3^{\circ} \mathrm{C}\right.$ for $\left.15 \mathrm{~min}\right)$ [120]. Reduced muscle and core temperatures following CWI have been proposed to be the major factors responsible for the detrimental effect of cooling on sprint performance [114, 115, 117, 122]. Older research showed that peak PO during cycling sprint declined proportionally to the reduction of muscle temperature (from 38 to $30^{\circ} \mathrm{C}$ ), a result attributed to a slower rate of force development [123]. In addition, this negative effect on performance is more marked for fast than slow movements $[123,124]$, which could explain why the detrimental effect of CWI is so apparent during Wingate tests. Muscle cooling could also increase muscle stiffness [125], as well as reduce enzyme activity [126], leading to a reduced anaerobic ATP production during sprint exercise. Furthermore, CWI leads to parasympathetic activation and sympathetic withdrawal [113], which could blunt the heart rate acceleration, thereby limiting cardiac output and $\mathrm{O}_{2}$ delivery to exercising muscles during the maximal sprints. $\mathrm{O}_{2}$ and nutrient supply during exercise could also be diminished by muscle cooling due to peripheral vasoconstriction and reduced blood flow to active muscles $[115,127]$. Finally, cooling-induced impairment in sprint performance could be partly related to a modification of neural drive and firing rate of motor units, and to reduced nerve conduction [124, 128]. Altogether, it appears that both peripheral and central factors contribute to impaired sprint performance after cooling.

Two studies did not observe any negative effect of CWI applied after a single cycling sprint on subsequent sprint performance $[113,118]$, a finding possibly explained by the absence of reduced temperature during the second sprint bout. In the study from Buchheit et al. (2009), trained cyclists performed a 1-km cycling sprint $(\sim 80 \mathrm{~s})$ in hot conditions $\left(35^{\circ} \mathrm{C}\right)$ before exposure to $\mathrm{CWI}\left(14{ }^{\circ} \mathrm{C}\right.$ for $5 \mathrm{~min}$ ) or passive recovery [113]. Rectal temperature was not different between the 2 conditions after exposure and during the subsequent $1-\mathrm{km}$ cycling sprint. In the study by Yoshimura et al., a Wingate test was performed 
following $10 \mathrm{~min}$ low intensity exercise, and whole-body $\mathrm{CWI}\left(20^{\circ} \mathrm{C}\right.$ for $20 \mathrm{~min}$ ) did not reduce sublingual temperature during the 2nd sprint [118]. Another study found that CWT $\left(1 \mathrm{~min}\right.$ at $8{ }^{\circ} \mathrm{C}$ and $4 \mathrm{~min}$ at $40{ }^{\circ} \mathrm{C}$ for $30 \mathrm{~min}: \mathrm{CWI} / \mathrm{HWI}=1 / 4)$ applied after 3 Wingate tests resulted in an improved maintenance of peak PO compared with passive recovery during subsequent cycling sprints [119]. However, this result was not as obvious when CWT alternated a 2.5 -min cold/2.5-min hot treatment $(\mathrm{CWI} / \mathrm{HWI}=1 / 1)$. Altogether, these findings suggest that for a sake of faster recovery, core and muscle temperatures should remain equal or slightly above normothermia following sprint exercises, and an additional slight increase in core/muscle temperature due to external heating may eventually be beneficial for improving subsequent sprint performance.

Only two studies investigated the effects of postexercise CWI on the recovery of jump performance (SJ and DJ) [121] and muscle strength (MVIC) [120] during the early period ( $1-2 \mathrm{~h}$ ) following sprint exercise. White et al. (2014) found that CWI conditions (10$20{ }^{\circ} \mathrm{C}$ for $10-30 \mathrm{~min}$ ) were not effective compared with passive recovery in restoring SJ and DJ performance when assessed at 1 and $2 \mathrm{~h}$ following 12 maximal running sprints $(120 \mathrm{~m})$ [121]. In the study by Broatch et al. (2014), 4 Wingate tests were performed before application of CWI $\left(10.3{ }^{\circ} \mathrm{C}\right.$ for $\left.15 \mathrm{~min}\right)$, TWI $\left(34.7{ }^{\circ} \mathrm{C}\right.$ for $15 \mathrm{~min}$ ) or TWI combined with a placebo (skin cleanser added to the water) [120]. Knee extension MVIC torque was similar directly after recovery intervention and at $1 \mathrm{~h}$ after exercise in both CWI and TWI-placebo conditions, while TWI alone had a negative effect on MVIC torque compared with TWI-placebo. To conclude, CWI is not effective in accelerating the recovery of jump performance and muscle strength immediately after recovery and $1-2 \mathrm{~h}$ following sprint exercises.

\section{Later Recovery Phase (24-48 h)}

The effects of post-exercise CWI on the recovery of jump performance (SJ and DJ) [121] and muscle strength (MVIC) [120] were assessed during the later recovery phase $(24-48 \mathrm{~h})$ following sprint exercises. In contrast to the absence of effect of CWI on SJ performance, DJ performance was fully recovered in CWI condition but not in passive recovery condition at $24 \mathrm{~h}\left(10{ }^{\circ} \mathrm{C}\right.$ for 10 and $30 \mathrm{~min})$ and $48 \mathrm{~h}\left(10^{\circ} \mathrm{C}\right.$ for $\left.10 \mathrm{~min}\right)$ following sprint exercises [121]. It was previously speculated that CWI could be inhibiting the type III and IV muscle afferents, which may facilitate the stretch reflex and its subsequent contribution to force production during DJ [121]. Furthermore, Broatch et al. showed that MVIC knee extension torque was greater in TWI $\left(34.7{ }^{\circ} \mathrm{C}\right.$ for $\left.15 \mathrm{~min}\right)$ combined with a placebo (skin cleanser added to the water) compared with TWI alone at $24 \mathrm{~h}$ (average torque) and $48 \mathrm{~h}$ (peak and average torques) after sprint exercises [120]. Peak MVIC torque was not different between CWI $\left(10.3{ }^{\circ} \mathrm{C}\right.$ for $15 \mathrm{~min}$ ) group and the two other groups (TWI and TWI-placebo) at 24 and $48 \mathrm{~h}$ post-exercise. Moreover, a tendency to greater average MVIC torque $(P=0.08)$ was shown at $48 \mathrm{~h}$ after exercise in the CWI group compared with the TWI group in this study, suggesting that the benefits of CWI on recovery of muscle function are partly placebo related [120]. Altogether, the findings of these two studies suggest that CWI applied after repeated sprint exercises has some benefits in accelerating the restoration of neuromuscular function during the later recovery phase.

\section{Repeated Post-exercise Cooling}

To our knowledge, only one study assessed the effects of repeated use of CWI on training adaptations following an intervention including sprint exercises [17], where recreationally active subjects performed $4-6 \times 30 \mathrm{~s}$ allout cycling sprints with 4 min of rest 3 times per week for 6 weeks. Performance $(2 \mathrm{~km}$ and $20 \mathrm{~km}$ cycling time trials), $\mathrm{VO}_{2 \text { peak }}$ and peak $\mathrm{PO}$ during incremental testing improved similarly with training for the group exposed to $\mathrm{CWI}\left(10^{\circ} \mathrm{C}\right.$ for $15 \mathrm{~min}$ after each session) and the control group (passive recovery). In the same study, CWI did not affect the acute and long-term molecular responses associated with muscle mitochondrial biogenesis and oxidative metabolism. Although it is difficult to draw definitive conclusions from one study, CWI employed after sprint exercises does not appear effective for augmenting endurance-training adaptations. Whether it would affect the development of sprint performance remains to be investigated.

\section{Summary}

- Early recovery period (immediate to $2 \mathrm{~h}$ ): negative effect of CWI and local cooling on sprint performance; no effect on recovery of jump performance and muscle strength.

- Later recovery period (24-48 h): some benefits of CWI on jump performance (DJ only) and muscle strength.

- Post-exercise recovery period on training adaptations: no effect of CWI.

\section{Conclusions}

This comprehensive review analyzed the effects of postexercise cooling and post-exercise heating on functional recovery and training adaptations and provides practical implications for coaches and athletes wanting to optimize 


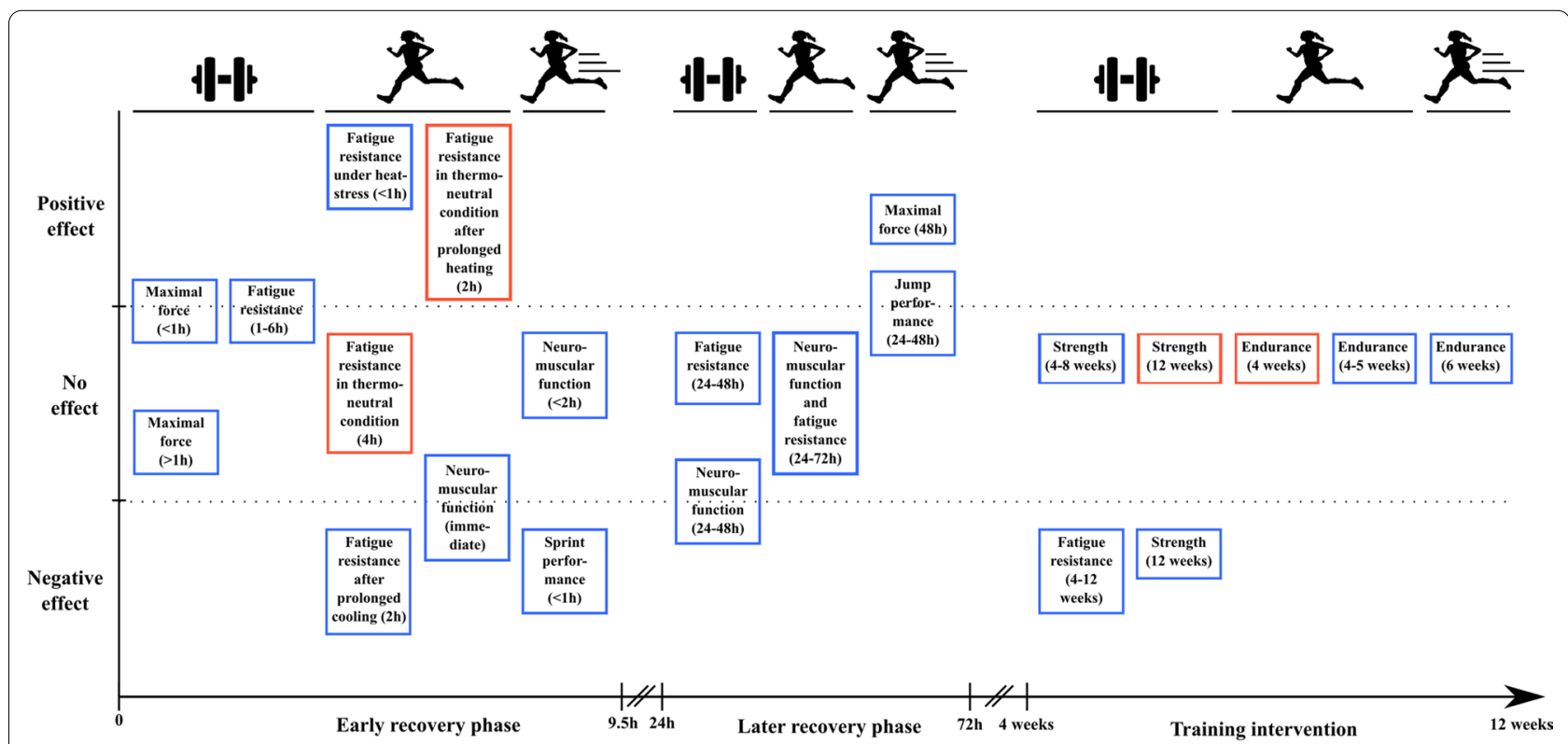

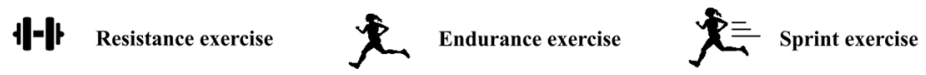

Fig. 1 Main effects of post-exercise cooling and heating on functional recovery and training adaptations. The blue boxes illustrate the specific effects of cooling, and the red boxes illustrate the specific effects of heating. These effects are based on the main conclusions drawn from the literature research and from Tables 1, 2, and 3

recovery and performance in their sport. A summary of the main effects of post-exercise cooling and heating is presented at the end of each section and is illustrated in Fig. 1. The effects of post-exercise cooling or heating depend on (1) the form and intensity of exercise performed, (2) the functional outcomes being assessed, (3) the post-exercise time period studied, (4) the ambient conditions, (5) the recovery protocol used and (6) whether recovery methods are used acutely or repeatedly. Other factors not discussed in this review may influence the effects of post-exercise cooling or heating such as the training status, sex [129], body composition [130], the genetic background [131], and the previous chronic exposure to cooling or heating.

We identified limited data employing heating as a recovery intervention in the various forms of exercise, and further research is warranted in this area, with the most promise being the use of HWI as a recovery intervention following endurance and sprint exercises. Major limitations of studies employing cooling and heating include the lack of a consistent control condition (e.g., active recovery, passive stretching, sitting), a lack of standardized cooling and heating protocols, the limited data available in elite athletes, and the paucity of long training interventions employing cooling/heating recovery methods. Moreover, since the benefits of CWI appear to be partly placebo related [120], it is surprising that only three studies included in this review used placebo methods $[31,100,120]$. A strong effort should be made in future studies to develop effective placebo conditions.

\section{Abbreviations}

1-RM: 1 Repetition maximum; AMPK: AMP kinase; ANGPT2: Angiopoietin 2; CMJ: Countermovement jump; CON: Control; CONC: Concentric; CWC: Cold water cuff; CWI: Cold water immersion; CWT: Contrast water therapy; DJ: Drop jump; ECC: Eccentric; eNOS: Endothelial nitric oxide synthase; ERK1/2: Extracellular signal-regulated kinase 1/2; Ex: Exercise; F: Female; $\mathrm{H}^{+}$: Hydrogen ion; HIIE: High intensity interval exercise; HWI: Hot water immersion; KE: Knee extension; KF: Knee flexion; M: Male; MVIC: Maximal voluntary isometric contraction; PGC1A: Peroxisome proliferator-activated receptor gamma coactivator 1-alpha; $P_{\text {: }}$ Inorganic phosphate; PLA: Placebo; Pmax: Maximal power obtained during a maximal incremental test; PO: Power output; PR: Passive recovery; Reps: Repetitions; RH: Relative humidity; RMS: Root mean square; RONS:

Reactive oxygen and nitrogen species; SERCA: Sarcoendoplasmic reticulum calcium transport ATPase; SJ: Squat jump; SMVIC: Maximal voluntary isometric contraction with superimposed electrical stimulation; SR: Sarcoplasmic reticulum; RE: Resistance exercise; RT: Resistance training; TT:Time trial; TWI: Thermoneutral water immersion; TWP: Thermoneutral water immersion with placebo; VA: Voluntary activation assessed via interpolated twitch technique; VEGF: Vascular endothelial growth factor; Vmax: Maximal speed obtained during a maximal incremental test; $\mathrm{VO}_{2}$ : Oxygen uptake; $\mathrm{VO}_{2 \text { max }}$ : Maximal oxygen uptake; VT: Ventilatory threshold; Wk: Week; Y: Year.

\section{Acknowledgements}

Open Access funding for this article was provided by Örebro University, Örebro, Sweden. 


\section{Authors' contributions}

The idea for the review was conceived by T.C. and A.J.C. T.C., A.J.C., V.S. and S.M. wrote the manuscript. T.C., V.S., S.M. and A.J.C. created the tables and V.S. and T.C. created the figure. T.V. and M.B. critically revised the manuscript. All authors read and approved the manuscript.

\section{Funding}

Open access funding provided by Örebro University. This work was supported by the Swedish Research Council for Sport Science (Thomas Chaillou; P20190119); the Natural Sciences and Engineering Research Council of Canada (NSERC) (Arthur Cheng; RGPIN-2020-06443, DGECR-2020-00136); and a Muscle Health Research Centre Student Fellowship Award (Sarah Mosely; York University, Toronto, Canada).

\section{Availability of Data and Materials}

Not applicable.

\section{Declarations}

\section{Ethics Approval and Consent to Participate}

Not applicable.

\section{Consent for Publication}

Not applicable.

\section{Competing interests}

Thomas Chaillou, Viktorija Treigyte, Sarah Mosely, Marius Brazaitis, Tomas Venckunas, and Arthur J. Cheng declare that they have no competing interests.

\section{Author details}

${ }^{1}$ School of Health Sciences, Örebro University, 70182 Örebro, Sweden. ${ }^{2}$ Sports Science and Innovation Institute, Lithuanian Sports University, 44221 Kaunas, Lithuania. ${ }^{3}$ Muscle Health Research Centre, School of Kinesiology and Health Sciences, Faculty of Health, York University, Toronto M3J 1P3, Canada.

Received: 4 July 2021 Accepted: 16 February 2022

Published online: 07 March 2022

\section{References}

1. Egan B, Zierath JR. Exercise metabolism and the molecular regulation of skeletal muscle adaptation. Cell Metab. 2013;17(2):162-84.

2. Versey NG, Halson SL, Dawson BT. Water immersion recovery for athletes: effect on exercise performance and practical recommendations. Sports Med. 2013;43(11):1101-30.

3. Hyldahl RD, Peake JM. Combining cooling or heating applications with exercise training to enhance performance and muscle adaptations. J Appl Physiol (1985). 2020;129(2):353-65.

4. Broatch JR, Petersen A, Bishop DJ. The influence of post-exercise coldwater immersion on adaptive responses to exercise: a review of the literature. Sports Med. 2018;48(6):1369-87.

5. Higgins TR, Greene DA, Baker MK. Effects of cold water immersion and contrast water therapy for recovery from team sport: a systematic review and meta-analysis. J Strength Cond Res. 2017;31(5):1443-60.

6. Insan M, Watson G, Abbiss CR. What are the physiological mechanisms for post-exercise cold water immersion in the recovery from prolonged endurance and intermittent exercise? Sports Med. 2016;46(8):1095-109.

7. McGorm H, Roberts LA, Coombes JS, Peake JM. Turning up the heat: an evaluation of the evidence for heating to promote exercise recovery, muscle rehabilitation and adaptation. Sports Med. 2018;48(6):1311-28.

8. Rodrigues P, Trajano GS, Wharton L, Minett GM. Effects of passive heating intervention on muscle hypertrophy and neuromuscular function: a preliminary systematic review with meta-analysis. J Therm Biol. 2020;93:102684.

9. Bleakley CM, Davison GW. What is the biochemical and physiological rationale for using cold-water immersion in sports recovery? A systematic review. Br J Sports Med. 2010;44(3):179-87.
10. Wilcock IM, Cronin JB, Hing WA. Physiological response to water immersion: a method for sport recovery? Sports Med. 2006;36(9):747-65.

11. Malta ES, Dutra YM, Broatch JR, Bishop DJ, Zagatto AM. The effects of regular cold-water immersion use on training-induced changes in strength and endurance performance: a systematic review with metaanalysis. Sports Med. 2021;51(1):161-74.

12. Allen DG, Lamb GD, Westerblad H. Skeletal muscle fatigue: cellular mechanisms. Physiol Rev. 2008;88(1):287-332.

13. Cheng AJ, Place N, Westerblad H. Molecular basis for exercise-induced fatigue: the importance of strictly controlled cellular $\mathrm{Ca}(2+)$ handling. Cold Spring Harb Perspect Med. 2018;8(2):a29710.

14. Lindsay A, Peake JM. Muscle strength and power: primary outcome measures to assess cold water immersion efficacy after exercise with a strong strength or power component. Front Sports Act Living. 2021;3:655975.

15. Stanley J, Peake JM, Buchheit M. Consecutive days of cold water immersion: effects on cycling performance and heart rate variability. Eur J Appl Physiol. 2013;113(2):371-84.

16. Vaile J, Halson S, Gill N, Dawson B. Effect of hydrotherapy on recovery from fatigue. Int J Sports Med. 2008;29(7):539-44.

17. Broatch JR, Petersen A, Bishop DJ. Cold-water immersion following sprint interval training does not alter endurance signaling pathways or training adaptations in human skeletal muscle. Am J Physiol Regul Integr Comp Physiol. 2017;313(4):R372-84.

18. Bishop DJ, Girard O. Determinants of team-sport performance: implications for altitude training by team-sport athletes. Br J Sports Med. 2013:47(Suppl 1):i17-21.

19. Cheng AJ, Willis SJ, Zinner C, Chaillou T, Ivarsson N, Ortenblad N, et al. Post-exercise recovery of contractile function and endurance in humans and mice is accelerated by heating and slowed by cooling skeletal muscle. J Physiol. 2017:595(24):7413-26.

20. Pointon M, Duffield R, Cannon J, Marino FE. Cold application for neuromuscular recovery following intense lower-body exercise. Eur J Appl Physiol. 2011;111(12):2977-86.

21. Kim S, Hurr C. Effects of acute cooling on cycling anaerobic exercise performance and neuromuscular activity: a randomized crossover study. J Sports Med Phys Fitness. 2020;60(11):1437-43.

22. De Paula F, Escobar K, Ottone V, Aguiar P, Aguiar de Matos M, Duarte $\mathrm{T}$, et al. Post-exercise cold-water immersion improves the performance in a subsequent 5-km running trial. Temperature (Austin). 2018;5(4):359-70.

23. Méline T, Solsona R, Antonietti JP, Borrani F, Candau R, Sanchez AM. Influence of post-exercise hot-water therapy on adaptations to training over 4 weeks in elite short-track speed skaters. J Exerc Sci Fit. 2021;19(2):134-42.

24. Zurawlew MJ, Walsh NP, Fortes MB, Potter C. Post-exercise hot water immersion induces heat acclimation and improves endurance exercise performance in the heat. Scand J Med Sci Sports. 2016;26(7):745-54.

25. Stadnyk AMJ, Rehrer NJ, Handcock PJ, Meredith-Jones KA, Cotter JD. No clear benefit of muscle heating on hypertrophy and strength with resistance training. Temperature (Austin). 2018:5(2):175-83.

26. Bove AA. Medical disorders related to diving. J Intensive Care Med. 2002;17(2):75-86

27. Smith RM, Hanna JM. Skinfolds and resting heat loss in cold air and water: temperature equivalence. J Appl Physiol. 1975;39(1):93-102.

28. Craig AB Jr, Dvorak M. Thermal regulation during water immersion. J Appl Physiol. 1966;21(5):1577-85.

29. Roberts LA, Nosaka K, Coombes JS, Peake JM. Cold water immersion enhances recovery of submaximal muscle function after resistance exercise. Am J Physiol Regul Integr Comp Physiol. 2014;307(8):R998-1008.

30. Roberts LA, Muthalib M, Stanley J, Lichtwark G, Nosaka K, Coombes JS, et al. Effects of cold water immersion and active recovery on hemodynamics and recovery of muscle strength following resistance exercise. Am J Physiol Regul Integr Comp Physiol. 2015;309(4):R389-98.

31. Wilson LJ, Dimitriou L, Hills FA, Gondek MB, Cockburn E. Whole body cryotherapy, cold water immersion, or a placebo following resistance exercise: a case of mind over matter? Eur J Appl Physiol. 2019;119(1):135-47.

32. Yamane M, Teruya H, Nakano M, Ogai R, Ohnishi N, Kosaka M. Postexercise leg and forearm flexor muscle cooling in humans attenuates 
endurance and resistance training effects on muscle performance and on circulatory adaptation. Eur J Appl Physiol. 2006;96(5):572-80.

33. Argus CK, Broatch JR, Petersen AC, Polman R, Bishop DJ, Halson S. Cold-water immersion and contrast water therapy: no improvement of short-term recovery after resistance training. Int I Sports Physiol Perform. 2017;12(7):886-92.

34. Fröhlich M, Faude O, Klein M, Pieter A, Emrich E, Meyer T. Strength training adaptations after cold-water immersion. J Strength Cond Res. 2014:28(9):2628-33.

35. Fyfe JJ, Broatch JR, Trewin AJ, Hanson ED, Argus CK, Garnham AP, et al. Cold water immersion attenuates anabolic signaling and skeletal muscle fiber hypertrophy, but not strength gain, following whole-body resistance training. J Appl Physiol (1985). 2019:127(5):1403-18.

36. Gonzalez AM, Stout JR, Jajtner AR, Townsend JR, Wells AJ, Beyer KS, et al. Effects of $\beta$-hydroxy- $\beta$-methylbutyrate free acid and cold water immersion on post-exercise markers of muscle damage. Amino Acids. 2014;46(6):1501-11.

37. Jajtner AR, Hoffman JR, Gonzalez AM, Worts PR, Fragala MS, Stout JR. Comparison of the effects of electrical stimulation and cold-water immersion on muscle soreness after resistance exercise. J Sport Rehabil. 2015;24(2):99-108.

38. Yamane M, Ohnishi N, Matsumoto T. Does regular post-exercise cold application attenuate trained muscle adaptation? Int J Sports Med. 2015:36(8):647-53.

39. Ohnishi N, Yamane M, Uchiyama N, Shirasawa S, Kosaka M, Shiono $\mathrm{H}$, et al. Adaptive changes in muscular performance and circulation by resistance training with regular cold application. J Therm Biol. 2004;29(7-8):839-43.

40. Kumazawa T, Mizumura K. Thin-fibre receptors responding to mechanical, chemical, and thermal stimulation in the skeletal muscle of the dog. J Physiol. 1977;273(1):179-94.

41. Pollak KA, Swenson JD, Vanhaitsma TA, Hughen RW, Jo D, White AT, et al. Exogenously applied muscle metabolites synergistically evoke sensations of muscle fatigue and pain in human subjects. Exp Physiol. 2014:99(2):368-80.

42. Gregory NS, Whitley PE, Sluka KA. Effect of intramuscular protons, lactate, and ATP on muscle hyperalgesia in rats. PLOS ONE. 2015:10(9):e0138576.

43. Bellezza PA, Hall EE, Miller PC, Bixby WR. The influence of exercise order on blood lactate, perceptual, and affective responses. J Strength Cond Res. 2009;23(1):203-8.

44. Gorostiaga EM, Navarro-Amézqueta I, Calbet JA, Sánchez-Medina L, Cusso R, Guerrero M, et al. Blood ammonia and lactate as markers of muscle metabolites during leg press exercise. J Strength Cond Res. 2014;28(10):2775-85.

45. Menzies P, Menzies C, McIntyre L, Paterson P, Wilson J, Kemi OJ. Blood lactate clearance during active recovery after an intense running bout depends on the intensity of the active recovery. J Sports Sci. 2010;28(9):975-82.

46. Cheng AJ, Neyroud D, Kayser B, Westerblad H, Place N. Intramuscular contributions to low-frequency force potentiation induced by a highfrequency conditioning stimulation. Front Physiol. 2017;8:712.

47. de Ruiter CJ, Jones DA, Sargeant AJ, de Haan A. Temperature effect on the rates of isometric force development and relaxation in the fresh and fatigued human adductor pollicis muscle. Exp Physiol. 1999;84(6):1137-50

48. Stienen GJ, Kiers JL, Bottinelli R, Reggiani C. Myofibrillar ATPase activity in skinned human skeletal muscle fibres: fibre type and temperature dependence. J Physiol. 1996;493(2):299-307.

49. Metcalf $E$, Hagstrom AD, Marshall PW. Trained females exhibit less fatigability than trained males after a heavy knee extensor resistance exercise session. Eur J Appl Physiol. 2019;119(1):181-90.

50. Woodward M, Debold EP. Acidosis and phosphate directly reduce myosin's force-generating capacity through distinct molecular mechanisms. Front Physiol. 2018;9:862.

51. Bogdanis GC, Nevill ME, Boobis LH, Lakomy HK, Nevill AM. Recovery of power output and muscle metabolites following $30 \mathrm{~s}$ of maximal sprint cycling in man. J Physiol. 1995;482(2):467-80.

52. Juel C, Klarskov C, Nielsen JJ, Krustrup P, Mohr M, Bangsbo J. Effect of high-intensity intermittent training on lactate and $\mathrm{H}+$ release from human skeletal muscle. Am J Physiol Endocrinol Metab. 2004;286(2):E245-51.

53. Poppendieck W, Wegmann M, Hecksteden A, Darup A, Schimpchen J, Skorski S, et al. Does cold-water immersion after strength training attenuate training adaptation? Int I Sports Physiol Perform. 2020;16(2):304-10.

54. Gabriel DA, Kamen G, Frost G. Neural adaptations to resistive exercise: mechanisms and recommendations for training practices. Sports Med. 2006;36(2):133-49.

55. Roberts LA, Raastad T, Markworth JF, Figueiredo VC, Egner IM, Shield A, et al. Post-exercise cold water immersion attenuates acute anabolic signalling and long-term adaptations in muscle to strength training. J Physiol. 2015;593(18):4285-301.

56. Earp JE, Hatfield DL, Sherman A, Lee EC, Kraemer WJ. Cold-water immersion blunts and delays increases in circulating testosterone and cytokines post-resistance exercise. Eur J Appl Physiol. 2019;119(8):1901-7.

57. Fuchs CJ, Kouw IWK, Churchward-Venne TA, Smeets JSJ, Senden JM, Lichtenbelt W, et al. Postexercise cooling impairs muscle protein synthesis rates in recreational athletes. J Physiol. 2020;598(4):755-72.

58. Place N, Ivarsson N, Venckunas T, Neyroud D, Brazaitis M, Cheng AJ, et al. Ryanodine receptor fragmentation and sarcoplasmic reticulum $\mathrm{Ca} 2+$ leak after one session of high-intensity interval exercise. Proc Natl Acad Sci USA. 2015:112(50):15492-7.

59. Henríquez-Olguín C, Renani LB, Arab-Ceschia L, Raun SH, Bhatia A, Li Z, et al. Adaptations to high-intensity interval training in skeletal muscle require NADPH oxidase 2. Redox Biol. 2019;24:101188.

60. Gomez-Cabrera MC, Domenech E, Romagnoli M, Arduini A, Borras C, Pallardo FV, et al. Oral administration of vitamin $C$ decreases muscle mitochondrial biogenesis and hampers training-induced adaptations in endurance performance. Am J Clin Nutr. 2008:87(1):142-9.

61. Paulsen G, Cumming KT, Holden G, Hallén J, Rønnestad BR, Sveen O, et al. Vitamin $C$ and $E$ supplementation hampers cellular adaptation to endurance training in humans: a double-blind, randomised, controlled trial. J Physiol. 2014;592(8):1887-901.

62. Ristow M, Zarse K, Oberbach A, Kloting N, Birringer M, Kiehntopf M, et al. Antioxidants prevent health-promoting effects of physical exercise in humans. Proc Natl Acad Sci USA. 2009;106(21):8665-70.

63. Strobel NA, Peake JM, Matsumoto A, Marsh SA, Coombes JS, Wadley GD. Antioxidant supplementation reduces skeletal muscle mitochondrial biogenesis. Med Sci Sports Exerc. 2011;43(6):1017-24.

64. Wyckelsma VL, Venckunas T, Brazaitis M, Gastaldello S, Snieckus A, Eimantas $\mathrm{N}$, et al. Vitamin $\mathrm{C}$ and $\mathrm{E}$ treatment blunts sprint interval training-induced changes in inflammatory mediator-, calcium-, and mitochondria-related signaling in recreationally active elderly humans. Antioxidants (Basel). 2020;9(9):879.

65. Pal R, Basu Thakur P, Li S, Minard C, Rodney GG. Real-time imaging of NADPH oxidase activity in living cells using a novel fluorescent protein reporter. PLoS ONE. 2013;8(5):e63989.

66. Sutkowy P, Woźniak A, Boraczyński T, Mila-Kierzenkowska C, Boraczyński M. Postexercise impact of ice-cold water bath on the oxidant-antioxidant balance in healthy men. Biomed Res Int. 2015;2015:706141.

67. Fuchs CJ, Smeets JSJ, Senden JM, Zorenc AH, Goessens JPB, van Marken Lichtenbelt WD, et al. Hot-water immersion does not increase postprandial muscle protein synthesis rates during recovery from resistance-type exercise in healthy, young males. J Appl Physiol (1985). 2020:128(4):1012-22.

68. Eimonte M, Paulauskas H, Daniuseviciute L, Eimantas N, Vitkauskiene A, Dauksaite $G$, et al. Residual effects of short-term whole-body cold-water immersion on the cytokine profile, white blood cell count, and blood markers of stress. Int J Hyperthermia. 2021;38(1):696-707.

69. Joo CH, Allan R, Drust B, Close GL, Jeong TS, Bartlett JD, et al. Passive and post-exercise cold-water immersion augments PGC-1alpha and VEGF expression in human skeletal muscle. Eur J Appl Physiol. 2016;1 16(11-12):2315-26

70. Goto K, Oda H, Kondo H, Igaki M, Suzuki A, Tsuchiya S, et al. Responses of muscle mass, strength and gene transcripts to long-term heat stress in healthy human subjects. Eur J Appl Physiol. 2011;111(1):17-27.

71. Hafen PS, Abbott K, Bowden J, Lopiano R, Hancock CR, Hyldahl RD. Daily heat treatment maintains mitochondrial function and attenuates 
atrophy in human skeletal muscle subjected to immobilization. J App Physiol (1985). 2019;127(1):47-57.

72. Kim K, Reid BA, Casey CA, Bender BE, Ro B, Song Q, et al. Effects of repeated local heat therapy on skeletal muscle structure and function in humans. J Appl Physiol (1985). 2020;128(3):483-92.

73. Maclnnis MJ, Gibala MJ. Physiological adaptations to interval training and the role of exercise intensity. J Physiol. 2017;595(9):2915-30.

74. Brophy-Williams N, Landers G, Wallman K. Effect of immediate and delayed cold water immersion after a high intensity exercise session on subsequent run performance. J Sports Sci Med. 2011;10(4):665-70.

75. Crampton D, Donne B, Warmington SA, Egaña M. Cycling time to failure is better maintained by cold than contrast or thermoneutral lower-body water immersion in normothermia. Eur J Appl Physiol. 2013;113(12):3059-67.

76. Dunne A, Crampton D, Egaña M. Effect of post-exercise hydrotherapy water temperature on subsequent exhaustive running performance in normothermic conditions. J Sci Med Sport. 2013;16(5):466-71.

77. McCarthy A, Mulligan J, Egaña M. Postexercise cold-water immersion improves intermittent high-intensity exercise performance in normothermia. Appl Physiol Nutr Met. 2016:41(11):1163-70.

78. Peiffer JJ, Abbiss CR, Watson G, Nosaka K, Laursen PB. Effect of a 5-min cold-water immersion recovery on exercise performance in the heat. $\mathrm{Br}$ J Sports Med. 2010;44(6):461-5.

79. Vaile J, Halson S, Gill N, Dawson B. Effect of cold water immersion on repeat cycling performance and thermoregulation in the heat. J Sports Sci. 2008;26(5):431-40.

80. Vaile J, O'Hagan C, Stefanovic B, Walker M, Gill N, Askew CD. Effect of cold water immersion on repeated cycling performance and limb blood flow. Br J Sports Med. 2011;45(10):825-9.

81. Yeargin SW, Casa DJ, McClung JM, Knight JC, Healey JC, Goss PJ, et al. Body cooling between two bouts of exercise in the heat enhances subsequent performance. J Strength Cond Res. 2006;20(2):383-9.

82. De Pauw K, Roelands B, Vanparijs J, Meeusen R. Effect of recovery interventions on cycling performance and pacing strategy in the heat. Int J Sports Physiol Perform. 2014;9(2):240-8.

83. Parkin JM, Carey MF, Zhao S, Febbraio MA. Effect of ambient temperature on human skeletal muscle metabolism during fatiguing submaximal exercise. J Appl Physiol (1985). 1999;86(3):902-8.

84. Stanley J, Buchheit M, Peake JM. The effect of post-exercise hydrotherapy on subsequent exercise performance and heart rate variability. Eur J Appl Physiol. 2012;112(3):951-61.

85. Rowsell GJ, Reaburn P, Toone R, Smith M, Coutts AJ. Effect of run training and cold-water immersion on subsequent cycle training quality in high-performance triathletes. J Strength Cond Res. 2014;28(6):1664-72.

86. Gregson W, Allan R, Holden S, Phibbs P, Doran D, Campbell I, et al. Postexercise cold-water immersion does not attenuate muscle glycogen resynthesis. Med Sci Sports Exerc. 2013;45(6):1174-81.

87. Versey N, Halson S, Dawson B. Effect of contrast water therapy duration on recovery of cycling performance: a dose-response study. Eur J Appl Physiol. 2011;111(1):37-46.

88. Versey NG, Halson SL, Dawson BT. Effect of contrast water therapy duration on recovery of running performance. Int J Sports Physiol Perform. 2012;7(2):130-40.

89. Slivka D, Tucker T, Cuddy J, Hailes W, Ruby B. Local heat application enhances glycogenesis. Appl Physiol Nutr Metab. 2012:37(2):247-51.

90. Tucker TJ, Slivka DR, Cuddy JS, Hailes WS, Ruby BC. Effect of local cold application on glycogen recovery. J Sports Med Phys Fitness. 2012;52(2):158-64.

91. Blackwood SJ, Hanya E, Katz A. Heating after intense repeated contractions inhibits glycogen accumulation in mouse EDL muscle: role of phosphorylase in post-exercise glycogen metabolism. Am J Physiol Cell Physiol. 2018;315(5):C706-13.

92. Blackwood SJ, Hanya E, Katz A. Effect of postexercise temperature elevation on postexercise glycogen metabolism of isolated mouse soleus muscle. J Appl Physiol (1985). 2019;126(4):1103-9.

93. Hanya E, Katz A. Increased temperature accelerates glycogen synthesis and delays fatigue in isolated mouse muscle during repeated contractions. Acta Physiol (Oxf). 2018;223(1):e13027.

94. Wiewelhove T, Schneider C, Döweling A, Hanakam F, Rasche C, Meyer T, et al. Effects of different recovery strategies following a half-marathon on fatigue markers in recreational runners. PLOS ONE. 2018;13(11):e0207313.

95. Peiffer JJ, Abbiss CR, Nosaka K, Peake JM, Laursen PB. Effect of cold water immersion after exercise in the heat on muscle function, body temperatures, and vessel diameter. J Sci Med Sport. 2009;12(1):91-6.

96. Peiffer JJ, Abbiss CR, Watson G, Nosaka K, Laursen PB. Effect of coldwater immersion duration on body temperature and muscle function. $J$ Sports Sci. 2009;27(10):987-93.

97. Dantas G, Barros A, Silva B, Belém L, Ferreira V, Fonseca A, et al. Coldwater immersion does not accelerate performance recovery after 10-km street run: randomized controlled clinical trial. Res Q Exerc Sport. 2020;91(2):228-38.

98. Stenson MC, Stenson MR, Matthews TD, Paolone VJ. 5000 meter run performance is not enhanced $24 \mathrm{hrs}$ after an intense exercise bout and cold water immersion. J Sports Sci Med. 2017;16(2):272-9.

99. Jensen L, Gejl KD, Ortenblad N, Nielsen JL, Bech RD, Nygaard T, et al. Carbohydrate restricted recovery from long term endurance exercise does not affect gene responses involved in mitochondrial biogenesis in highly trained athletes. Physiol Rep. 2015;3(2):e12184.

100. Wilson L, Cockburn E, Paice K, Sinclair S, Faki T, Hills FA, et al. Recovery following a marathon: a comparison of cold water immersion, whole body cryotherapy and a placebo control. Eur J Appl Physiol. 2018;118(1):153-63.

101. Chauvineau M, Pasquier F, Guyot V, Aloulou A, Nedelec M. Effect of the depth of cold water immersion on sleep architecture and recovery among well-trained male endurance runners. Front Sports Act Living. 2021;3:659990

102. Saugy J, Place N, Millet GY, Degache F, Schena F, Millet GP. Alterations of neuromuscular function after the world's most challenging mountain ultra-marathon. PLoS ONE. 2013;8(6):e65596.

103. Millet GY, Tomazin $K$, Verges S, Vincent C, Bonnefoy R, Boisson RC, et al. Neuromuscular consequences of an extreme mountain ultra-marathon. PLoS ONE. 2011;6(2):e17059.

104. Aguiar PF, Magalhaes SM, Fonseca IA, da Costa Santos VB, de Matos $M A$, Peixoto MF, et al. Post-exercise cold water immersion does not alter high intensity interval training-induced exercise performance and Hsp72 responses, but enhances mitochondrial markers. Cell Stress Chaperones. 2016;21(5):793-804.

105. Halson SL, Bartram J, West N, Stephens J, Argus CK, Driller MW, et al. Does hydrotherapy help or hinder adaptation to training in competitive cyclists? Med Sci Sports Exerc. 2014;46(8):1631-9.

106. Ihsan M, Markworth JF, Watson G, Choo HC, Govus A, Pham T, et al. Regular postexercise cooling enhances mitochondrial biogenesis through AMPK and p38 MAPK in human skeletal muscle. Am J Physiol Regul Integr Comp Physiol. 2015;309(3):R286-94.

107. Allan R, Sharples AP, Close GL, Drust B, Shepherd SO, Dutton J, et al. Postexercise cold water immersion modulates skeletal muscle PGC-1alpha mRNA expression in immersed and nonimmersed limbs: evidence of systemic regulation. J Appl Physiol (1985). 2017;123(2):451-9.

108. Ihsan M, Watson G, Choo HC, Govus A, Cocking S, Stanley J, et al. Skeletal muscle microvascular adaptations following regular cold water immersion. Int J Sports Med. 2020;41(2):98-105.

109. Hafen PS, Preece CN, Sorensen JR, Hancock CR, Hyldahl RD. Repeated exposure to heat stress induces mitochondrial adaptation in human skeletal muscle. J Appl Physiol (1985). 2018;125(5):1447-55.

110. Ihsan M, Deldicque L, Molphy J, Britto F, Cherif A, Racinais S. Skeletal muscle signaling following whole-body and localized heat exposure in humans. Front Physiol. 2020;11:839.

111. Kuhlenhoelter AM, Kim K, Neff D, Nie Y, Blaize AN, Wong BJ, et al. Heat therapy promotes the expression of angiogenic regulators in human skeletal muscle. Am J Physiol Regul Integr Comp Physiol. 2016:311(2):R377-91.

112. Gibala MJ. Physiological basis of interval training for performance enhancement. Exp Physiol. 2021:106:2324-7.

113. Buchheit M, Peiffer JJ, Abbiss CR, Laursen PB. Effect of cold water immersion on postexercise parasympathetic reactivation. Am J Physiol Heart Circ Physiol. 2009;296(2):H421-7.

114. Crampton D, Egaña M, Donne B, Warmington SA. Including arm exercise during a cold water immersion recovery better assists restoration of sprint cycling performance. Scand J Med Sci Sports. 2014:24(4):e290-8. 
115. Crowe MJ, O'Connor D, Rudd D. Cold water recovery reduces anaerobic performance. Int J Sports Med. 2007;28(12):994-8.

116. Hurrie DMG, Giesbrecht GG. Is active recovery during cold water immersion better than active or passive recovery in thermoneutral water for postrecovery high-intensity sprint interval performance? Appl Physiol Nutr Metab. 2020;45(3):251-7.

117. Schniepp J, Campbell TS, Powell KL, Pincivero DM. The effects of coldwater immersion on power output and heart rate in elite cyclists. J Strength Cond Res. 2002;16(4):561-6.

118. Yoshimura M, Hojo T, Yamamoto H, Tachibana M, Nakamura M, Fukuoka Y. Effects of artificial $\mathrm{CO}(2)$-rich cold-water immersion on repeatedcycling work efficiency. Res Sports Med. 2022;30(2):215-27.

119. Crampton D, Donne B, Egaña M, Warmington SA. Sprint cycling performance is maintained with short-term contrast water immersion. Med Sci Sports Exerc. 2011;43(11):2180-8.

120. Broatch JR, Petersen A, Bishop DJ. Postexercise cold water immersion benefits are not greater than the placebo effect. Med Sci Sports Exerc. 2014:46(11):2139-47.

121. White GE, Rhind SG, Wells GD. The effect of various cold-water immersion protocols on exercise-induced inflammatory response and functional recovery from high-intensity sprint exercise. Eur J Appl Physiol. 2014;114(11):2353-67.

122. Parouty J, Al Haddad H, Quod M, Leprêtre PM, Ahmaidi S, Buchheit M. Effect of cold water immersion on 100-m sprint performance in welltrained swimmers. Eur J Appl Physiol. 2010;109(3):483-90.

123. Bergh $U$, Ekblom B. Influence of muscle temperature on maximal muscle strength and power output in human skeletal muscles. Acta Physiol Scand. 1979;107(1):33-7.

124. Racinais S, Oksa J. Temperature and neuromuscular function. Scand J Med Sci Sports. 2010;20(Suppl 3):1-18.

125. Faulkner JA, Zerba E, Brooks SV. Muscle temperature of mammals: cooling impairs most functional properties. Am J Physiol. 1990;259(2 Pt 2):R259-65.

126. Tattersall GJ, Sinclair BJ, Withers PC, Fields PA, Seebacher F, Cooper CE, et al. Coping with thermal challenges: physiological adaptations to environmental temperatures. Compr Physiol. 2012;2(3):2151-202.

127. Mawhinney C, Low DA, Jones H, Green DJ, Costello JT, Gregson W. Cold water mediates greater reductions in limb blood flow than whole body cryotherapy. Med Sci Sports Exerc. 2017:49(6):1252-60.

128. Algafly AA, George KP. The effect of cryotherapy on nerve conduction velocity, pain threshold and pain tolerance. Br J Sports Med. 2007:41(6):365-9 (discussion 369)

129. Boehm KE, Miller KC. Does gender affect rectal temperature cooling rates? A critically appraised topic. J Sport Rehabil. 2019;28(5):522-5.

130. Stephens JM, Halson SL, Miller J, Slater GJ, Chapman DW, Askew CD Effect of body composition on physiological responses to cold-water immersion and the recovery of exercise performance. Int J Sports Physiol Perform. 2018;13(3):382-9.

131. Wyckelsma VL, Venckunas T, Houweling PJ, Schlittler M, Lauschke VM, Tiong CF, et al. Loss of a-actinin-3 during human evolution provides superior cold resilience and muscle heat generation. Am J Hum Genet. 2021;108(3):446-57.

\section{Publisher's Note}

Springer Nature remains neutral with regard to jurisdictional claims in published maps and institutional affiliations.

\section{Submit your manuscript to a SpringerOpen ${ }^{\circ}$ journal and benefit from:}

- Convenient online submission

- Rigorous peer review

- Open access: articles freely available online

- High visibility within the field

- Retaining the copyright to your article

Submit your next manuscript at $\boldsymbol{\nabla}$ springeropen.com 